\title{
A Review of Antarctic Surface Snow Isotopic Composition: Observations, Atmospheric Circulation, and Isotopic Modeling*
}

\author{
V. Masson-Delmotte, ${ }^{a}$ S. Hou, ${ }^{b}$ A. Ekaykin, ${ }^{c}$ J. Jouzel,${ }^{a}$ A. Aristarain, ${ }^{d}$ R. T. Bernardo, ${ }^{\mathrm{e}}$ \\ D. Bromwich, ${ }^{\mathrm{f}}$ O. Cattani, ${ }^{\mathrm{a}}$ M. Delmotte, ${ }^{\mathrm{a}}$ S. Falourd,${ }^{\mathrm{a}}$ M. Frezzotti,${ }^{\mathrm{g}}$ H. Gallée, ${ }^{\mathrm{h}}$ L. Genoni, ${ }^{\mathrm{i}}$ \\ E. IsAKsson,${ }^{j}$ A. Landais, ${ }^{\mathrm{a}, \mathrm{k}}$ M. M. Helsen, ${ }^{1}{ }^{\mathrm{a}}$ G. Hoffmann, ${ }^{\mathrm{a}}{ }^{\mathrm{J}}$. Lopez,${ }^{\mathrm{m}}$ V. Morgan,${ }^{\mathrm{n}}$ H. Motoyama, ${ }^{\mathrm{o}}$ \\ D. Noone, ${ }^{\mathrm{p}}$ H. Oerter, ${ }^{\mathrm{q}}$ J. R. Petit, ${ }^{\mathrm{h}}$ A. Royer, ${ }^{\mathrm{a}}$ R. Uemura, ${ }^{\circ}$ G. A. Schmidt, ${ }^{\mathrm{r}}$ E. Schlosser, ${ }^{\mathrm{s}}$ \\ J. C. Simões, ${ }^{e}$ E. J. Steig, ${ }^{t}$ B. Stenni, ${ }^{i}$ M. Stievenard, ${ }^{a}$ M. R. van den Broeke, ${ }^{1}$ \\ R. S. W. van DE WAL, ${ }^{1}$ W. J. van de Berg, ${ }^{1}$ F. Vimeux, ${ }^{\mathrm{a}, \mathrm{u}}$ J. W. C. White ${ }^{\mathrm{v}}$ \\ ${ }^{a}$ Laboratoire des Sciences du Climat et de l'Environnement, IPSL/CEA-CNRS-UVSQ, Saclay, Gif-sur-Yvette, France \\ ${ }^{\mathrm{b}}$ Laboratory of Cryosphere and Environment, Chinese Academy of Sciences, Lanzhou, China \\ ${ }^{\mathrm{c}}$ Arctic and Antarctic Research Institute, St. Petersburg, Russia \\ ${ }^{\mathrm{d}}$ Laboratorio de Estratigrafía Glaciar y Geoquímica del Agua y de la Nieve, Instituto Antártico Argentino, Mendoza, Argentina \\ ${ }^{\mathrm{e}}$ Nucleo de Pesquisas Antarcticas e Climaticas, Departmento de Geografia, Instituto de Geociencias, Universidade Federal do Rio \\ Grande do Sul, Porto Alegre, Brazil \\ ${ }^{\mathrm{f}}$ The Ohio State University, Columbus, Ohio \\ ${ }^{\mathrm{g}}$ ENEA, Rome, Italy \\ ${ }^{\mathrm{h}}$ Laboratoire de Glaciologie et de Géophysique de l'Environnement, CNRS-Université Joseph Fourier, Saint Martin d'Hères, France \\ ${ }^{i}$ Department of Geological, Environmental and Marine Sciences, University of Trieste, Trieste, Italy \\ j Norwegian Polar Institute, Tromsǿ, Norway \\ ${ }^{\mathrm{k}}$ Earth Science Institute, Hebrew University, Jerusalem, Israel \\ ${ }^{1}$ Institute for Marine and Atmospheric Research, Utrecht University, Utrecht, Netherlands \\ ${ }^{\mathrm{m}}$ Departamento de Geologica y Geoquimica, Universidad Autonoma de Madrid, Madrid, Spain \\ ${ }^{\mathrm{n}}$ Antarctic Climate and Ecosystems CRC, and Australian Antarctic Division, Hobart, Australia \\ ${ }^{\circ}$ National Institute of Polar Research, Research Organization of Information and Systems, Tokyo, Japan \\ ${ }^{\mathrm{p}}$ Department of Atmospheric and Oceanic Sciences, and Cooperative Institute for Research in Environmental Sciences, University of \\ Colorado, Boulder, Colorado \\ ${ }^{\mathrm{q}}$ Alfred-Wegener-Institute für Polar und Meeresforschung, Bremerhaven, Germany \\ ${ }^{\mathrm{r}}$ NASA GISS, New York, New York \\ ${ }^{\mathrm{s}}$ Institute of Meteorology and Geophysics, University of Innsbruck, Innsbruck, Austria \\ ${ }^{\mathrm{t}}$ Department of Earth and Space Sciences, University of Washington, Seattle, Washington \\ ${ }^{\mathrm{u}} U R$ Greatice, IRD, Paris, France \\ ${ }^{v}$ INSTAAR, Boulder, Colorado
}

(Manuscript received 6 July 2007, in final form 27 November 2007)

\begin{abstract}
A database of surface Antarctic snow isotopic composition is constructed using available measurements, with an estimate of data quality and local variability. Although more than 1000 locations are documented, the spatial coverage remains uneven with a majority of sites located in specific areas of East Antarctica. The database is used to analyze the spatial variations in snow isotopic composition with respect to geographical characteristics (elevation, distance to the coast) and climatic features (temperature, accumulation) and with a focus on deuterium excess. The capacity of theoretical isotopic, regional, and general circulation atmospheric models (including "isotopic" models) to reproduce the observed features and assess the role of moisture advection in spatial deuterium excess fluctuations is analyzed.
\end{abstract}

\footnotetext{
* European Project for Ice Coring in Antarctica Publication Number 188 and Laboratoire des Sciences du Climat et l'Environnement Contribution Number 2739.
}

Corresponding author address: Valérie Masson-Delmotte, Laboratoire des Sciences du Climat et de l'Environnement, IPSL/CEACNRS-UVSQ, UMR 1572, Bat 701, L'Orme des Merisiers CEA, Saclay, 91191 Gif-sur-Yvette CEDEX, France.

E-mail: valerie.masson@cea.fr 


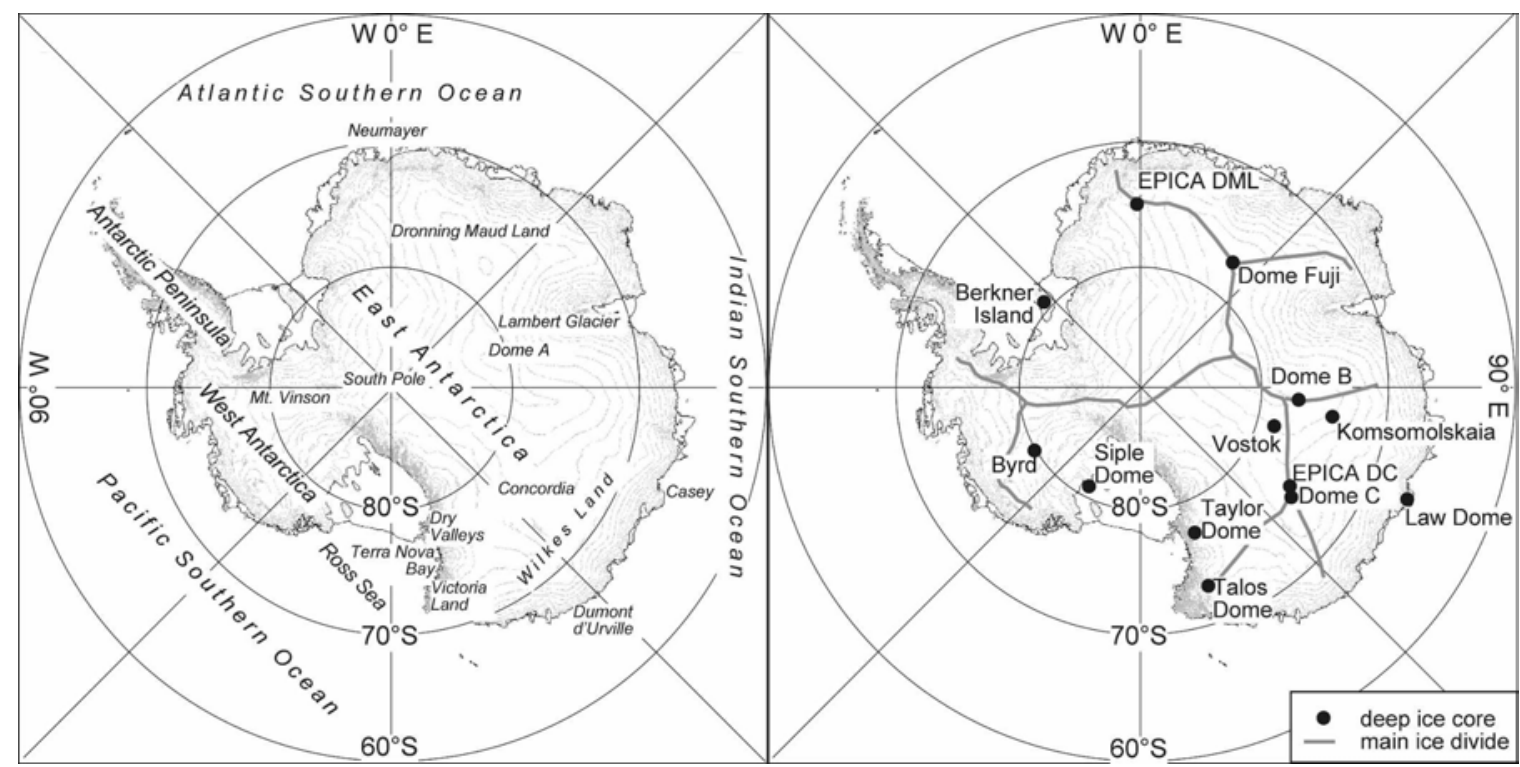

FIG. 1. Map of Antarctic topography showing (left) the names of different geographical sectors mentioned in the text and (right) the main deep ice core sites together with the main ice divide.

\section{Introduction}

Since the 1950s, it has been observed that the stable isotopic composition of precipitation in the mid- and high latitudes is related to air temperature (Dansgaard 1953; Epstein and Mayeda 1953; Craig 1961). In Antarctica (Fig. 1), surface snow was sampled along traverses to inland stations and firn temperature measurements were used as indicators of annual mean surface temperature (Epstein et al. 1963). Early studies were conducted to determine the spatial relationship between precipitation isotopic composition and local temperature (Lorius et al. 1969).

Assuming that this relationship remains valid over time, these calibrations were then used as an "isotopic thermometer" to quantify past changes in temperature based on the stable isotopic composition of deep ice cores, such as the recently obtained Eupropean Project for Ice Coring in Antarctica (EPICA) ice cores drilled at Dome C (DC; EPICA Community Members 2004) and in Dronning Maud Land (DML; EPICA Community Members 2006). In Greenland, the use of the spatial isotope-temperature slope has been challenged by alternative paleothermometry methods, such as the inversion of the borehole temperature profile (Cuffey et al. 1992; Johnsen et al. 1995), and the thermal and gravitational diffusion of air in the firn arising during abrupt climate changes (Severinghaus et al. 1998; Lang et al. 1999; Landais et al. 2004a,b,c).

In central East Antarctica, inversion of the borehole temperature profiles is problematic because of the low accumulation rates (Salamatin et al. 1998). Because Antarctic climate changes are less rapid than in Greenland, the gas fractionation method is problematic and cannot be used easily to quantify past temperature changes (Caillon et al. 2001; Landais et al. 2006). However, the stable isotope profiles derived from East Antarctic ice cores can be directly used to estimate past changes in accumulation through relationships between stable isotopes, air temperature, and saturation vapor pressure that are included in inversed glaciological dating methods (Parrenin et al. 2001). The dating of deep ice cores itself, when constrained by age markers, can be used to assess the stability of the isotope-temperature relationship back in time. When applied to inland Antarctic sites, such as Vostok (Parrenin et al. 2001), Dome Fuji (Watanabe et al. 2003), or EPICA Dome C (EPICA Community Members 2004), inverse methods suggest that the present-day-observed isotope-temperature slopes remain valid for past periods within $20 \%-$ $30 \%$, consistent with estimates provided by atmospheric general circulation models (AGCMs) (Jouzel et al. 2003).

Obtaining past temperature reconstructions together with a precise estimate of their uncertainties remains critical for the understanding of the natural pacing of Antarctic temperature (and accumulation) changes. A recent synthesis effort conducted over the past $200 \mathrm{yr}$ using well-dated ice cores has revealed strong interannual and decadal variability, with antiphase behavior between the Antarctic Peninsula and the inland sites, and the impact of the Southern Hemisphere $(\mathrm{SH})$ an- 
nular mode on Antarctic temperature variability (Schneider et al. 2006), together with the variability associated with ENSO (Schneider and Noone 2007). The Antarctic-scale coherence of temperature change remains uncertain at lower frequencies. A stack of five central Antarctic ice cores stable isotope records also suggests a small magnitude $\left(\sim 0.2^{\circ} \mathrm{C}\right)$ of common centennial-scale temperature variability (Goosse et al. 2004). Regional Antarctic temperature and accumulation reconstructions are essential for forcing Antarctic ice sheet models and for understanding the Antarctic ice sheet mass balance and dynamical reaction to changing climate and sea level. Because stable isotope records may be affected by changes in moisture origin, syntheses of stable isotope records should be performed over areas with similar moisture origins (Reijmer et al. 2002). Regional Antarctic temperature reconstructions are also essential for the comparison between observed past climatic changes and simulations performed by AGCMs, conducted only for the inland East Antarctic plateau (Masson-Delmotte et al. 2006).

In parallel, the factors controlling the isotopic composition of Antarctic snowfall have been analyzed based on a hierarchy of modeling approaches (Table 1). Distillation models calculate the theoretical fractionation that occurs along a cooling path with prescribed initial evaporation and condensation conditions. Such models have been used to assess the impact of equilibrium and kinetic fractionation processes on the snowfall isotopic composition (Merlivat and Jouzel 1979; Jouzel and Merlivat 1984). The second-order isotopic parameter deuterium excess $d=\delta \mathrm{D}-8 \times \delta^{18} \mathrm{O}$ (Dansgaard 1964) is expected to be highly sensitive to kinetic effects occurring either during evaporation at the ocean surface or during atmospheric transport (e.g., reevaporation of droplets or ice crystal formation). The observed high deuterium excess values of inland Antarctic snow cannot be simulated without taking into account kinetic fractionation in supersaturation conditions over ice crystals (Jouzel and Merlivat 1984; Salamatin et al. 2004). Sensitivity tests conducted with distillation models suggest that spatial variations of deuterium excess in Antarctica may reflect, at least partly, different moisture origins (Ciais and Jouzel 1994; Ciais et al. 1995; Kavanaugh and Cuffey 2003; Masson-Delmotte et al. 2004).

AGCMs equipped with the explicit representation of water-stable isotopes (Joussaume et al. 1984; Jouzel et al. 1987b, 1991; Hoffmann et al. 2000) allow us to disentangle the different factors involved in the spatial (Brown and Simmonds 2004; Schmidt et al. 2005), seasonal (Koster et al. 1992; Delmotte et al. 2000), inter- annual (Werner et al. 2001; Werner and Heimann 2002; Noone and Simmonds 2002a), or glacial-interglacial changes (Delaygue et al. 2000) in Antarctic snow isotopic composition. They offer the advantage of a consistent frame where tracers can be used to tag moisture of different geographical origins (Koster et al. 1986; Delaygue et al. 2000).

From these modeling efforts, it appears that the key factors controlling the observed distribution of stable isotopes in Antarctic snow are related to spatial changes of the integrated condensation temperature (including changes along the vapor trajectory, vertical changes, and the intermittency of snowfall days), and the origin of moisture (transported either at different elevations or from different geographical areas). In principle, condensation temperature during snowfall episodes should be the relevant climatic parameter used to analyze the spatial distribution of stable isotopes. Because only very few records of Antarctic condensation temperature are available, inversion temperature has been used as a surrogate for condensation temperature (Jouzel and Merlivat 1984). A detailed study for Vostok (Ekaykin 2003) confirmed the validity of this assumption for central Antarctica. However, this study highlighted that most of the local accumulation does not arise from cloud condensation, but from clearsky deposition of diamond dust. Until now, the comparison between AGCMs and isotopic data has not been focused on the different types of precipitation.

Biases of the simulated spatial distribution for the Antarctic surface air temperature range and of the amount or origin of snowfall can induce difficulties in the comparison of AGCM results with Antarctic isotopic data. To analyze the stable isotopic composition of snowfall in a model framework that is compatible with the observed climatology, several methods must be combined. For example, background fields of transport that are more consistent with observations can be provided by nudging AGCMs with reanalyses (Yoshimura et al. 2004; Noone 2006). Regional atmospheric models can also be used to simulate local features of the Antarctic atmospheric circulation and to analyze the factors controlling the regional origin of Antarctic moisture.

Atmospheric reanalyses are used to calculate back trajectories for individual Antarctic snowfall events. Along the back trajectories, distillation models can be implemented to estimate the snowfall isotopic composition (Helsen et al. 2007). Because the backward trajectories generally do not capture the evaporation process in the moisture source areas, monthly mean fields of atmospheric water vapor isotopic composition simulated by general circulation models have been used to initialize vapor isotopic composition for trajectory cal- 
TABLE 1. Hierarchy of modeling approaches used to analyze the processes responsible for the isotopic composition of Antarctic snowfall.

\begin{tabular}{cc}
\hline Method & \multicolumn{1}{c}{ References } \\
\hline $\begin{array}{l}\text { Rayleigh or mixed phase } \\
\text { distillation model }\end{array}$ & Jouzel and Merlivat (1984), \\
& Jouzel (1986), \\
& Fisher (1990), Ciais and \\
& Jouzel (1994), Kavanaugh \\
& and Cuffey (2003), and \\
& Salamatin et al. (2004)
\end{tabular}

Atmospheric general circulation models equipped with the explicit modeling of water-stable isotopes

Joussaume et al. (1984), Jouzel et al. (1987b), Hoffmann et al. (1998, 2000), Werner and Heimann (2002), Noone
Identification of synoptic weather characteristics and back trajectories for snowfall events using atmospheric reanalyses and Simmonds (1998), and Schmidt et al. (2005)

Reijmer et al. (2002) and Schlosser et al. (2004)

Helsen et al. (2007)

Simple isotopic model calculations along back trajectories using AGCM water vapor climatological distribution

Nudging of iso-AGCMs with reanalyses

Regional atmospheric models nudged with reanalyses

Regional atmospheric models with the explicit modeling of stable isotopes

Noone (2006)

Gallee et al. (2001), Bromwich et al. (2004), and van den Broeke and van Lipzig (2005)

Sturm et al. (2005)
Intrinsic model coherency

Full coupling between meteorological conditions and distillation

Possibility to explore the temporal stability of spatial relationships in response to various climate forcings

Realistic synoptic framework

Possibility to relate clusters of snowfall events to synoptic weather systems using their isotopic composition

Quantify the impact of airmass origins on final moisture isotopic composition

No hypothesis on condensation temperature (derived from reanalyses)

Advantages of mesoscale models with the coherency between atmospheric dynamics and isotopes of water dynamical framework coherent with observations

Good representation of key processes relevant for Antarctic precipitation (cloud microphysics, boundary layer, postdepositional effects)
Assumption on initial evaporation conditions (closure equation or iso-AGCM water vapor fields)

Assumption on the relationship between condensation and surface temperature

Poor representation of convection processes (not a key limitation for inland Antarctica)

Potential biases in model climatologies, especially in Antarctica

Limitations resulting from model resolution and adaptation of parameterizations for Antarctica (katabatic winds, boundary layer processes, stratospheric processes, cloud microphysics)

Difficult to isolate the relative role of different processes (moisture origin, trajectory, condensation, etc.)

Difficult to isolate the relative role of different processes (moisture origin, trajectory, condensation, etc.) on final precipitation isotopic composition

Difficult to follow moisture transport in the back trajectories

Possible incoherencies between iso-AGCM water vapor isotopic composition fields and back trajectories from reanalyses

Limited representation of convective processes

See section on iso-AGCM regarding AGCM limitations

Difficult to follow moisture transport

Difficult to isolate the relative role of different processes (moisture origin, trajectory, condensation, etc.) on final precipitation isotopic composition

Not yet achieved for Antarctica 
culations (Helsen et al. 2006). Backward air trajectories calculated for different Antarctic areas (Reijmer et al. 2002; Helsen et al. 2006) showed different moisture transport paths for coastal areas, where seasonal convection and cyclonic activity play a large role, and inland sites, where clear-sky precipitation may be a dominant contribution to local snowfall (Ekaykin 2003).

Parallel with these improvements on the modeling side, intensive field campaigns have been carried out in various sectors of Antarctica, including coordinated international traverses and presite surveys in search of optimal deep-drilling sites (Table 2). In this work, we have compiled a database of the available measurements of snowfall, surface snow, or firn core isotopic composition, taking into account their local variability. This database predominantly includes published measurements of Antarctic snow isotopic composition, and some unpublished data (Table 2) prior to the new field campaigns planned during the fourth International Polar Year.

The second section describes the various datasets, the quality control methodology, and the assessment of uncertainties, as well as the resulting spatial distribution of Antarctic snow-stable isotopic composition. The third section is focused on the comparison between these observations and a variety of model results based on simple isotopic models, regional atmospheric models, and isotopic AGCMs. The main outcomes of the paper and suggested ways forward are presented in the conclusions.

\section{A database of Antarctic snow isotopic composition}

\section{a. Sampling sites and related documentation}

Table 2 presents the list and references of the various sources of information compiled to produce the full Antarctic database (available as an Excel file online at http://www.lsce.ipsl.fr/Pisp/24/valerie.masson-delmotte. html). When available, we have included geographical information on the sampling location, such as annual mean temperature (estimated either from firn temperature measurements or automatic weather station surface air monitoring), latitude, longitude, and elevation (Fig. 2). In some cases, estimates of local accumulation rates are available, based on the identification of annual layers and reference horizons (e.g., Frezzotti et al. 2005). To quantify the continentality of the sites, we have estimated the horizontal distance to the nearest coast using the Antarctic coastline (this measurement may not reflect the distance along moisture trajectories, which is important for isotope physics). We have not included error bars on the estimates of annual mean temperature and accumulation rate because of a lack of consistent methodologies to evaluate these uncertainties.

The surface snow isotopic composition has been measured from direct precipitation sampling at a few sites [Global Network for Isotopes in Precipitation (GNIP) stations from the following International Atomic Energy Agency (IAEA) stations: Neumayer, Dumont d'Urville, Vostok, and Dome Fuji] over varying durations, sometimes over $1 \mathrm{yr}$ (Motoyama et al. 2005; Fujita and Abe 2006) or, for Neumayer, continuously since 1981 (Schlosser et al. 2004). Most surface snow samples have been collected along traverses conducted by individual groups or coordinated within the International Trans-Antarctic Scientific Expeditions (ITASE; Mayewski et al. 2005).

Surface snow-sampling procedures differ significantly from one site to another. In some cases, shallow snow cores or pits, typically $1 \mathrm{~m}$ deep, were sampled and one or several measurements were performed. In other cases, longer firn or ice cores have been analyzed with a subannual resolution. The database includes a description of the depth range and, if available, the temporal range (dating). In places where deep firn or ice cores have been drilled, meteorological data and detailed snow measurements are available. In some cases, there is no seasonal resolution either because of the low accumulation rates or the crude measurement resolution.

Finally, for each location we have reported the snow isotopic composition $\left(\delta \mathrm{D}, \delta^{18} \mathrm{O}\right.$, and deuterium excess $d$ ), in per mille (\%o) with respect to the Vienna Standard Mean Ocean Water (V-SMOW). When more than five measurements were performed at the same location (corresponding either to detailed measurements on a firn profile or to seasonal samples of snowfall), we have also included basic statistics (number, mean, maximum, minimum values, and standard deviation of the measurements) in the table. The country where the measurements were performed is also indicated.

The final database includes 1279 locations, out of which 938 have $\delta \mathrm{D}$ measurements, 1125 have $\delta^{18} \mathrm{O}$ measurements, and 794 have both isotopes, making it possible to calculate the deuterium excess (Fig. 3). For each site, deuterium excess values were calculated from individual measurements of $\delta \mathrm{D}$ and $\delta^{18} \mathrm{O}$ conducted on the same samples. Note that for each site we have calculated an average of all $\delta \mathrm{D}$ data available, an average of all $\delta^{18} \mathrm{O}$ data available, and an average of deuterium excess data (which may be on a restricted subset of data for which both isotopes have been measured). Therefore, the reported deuterium excess is not systematically identical to $\delta \mathrm{D}-8 \delta^{18} \mathrm{O}$ calculated from the mean 
TABLE 2. Data sources and references for previously published isotopic values or new data ("this study") as well as the type of data (snowfall, pits, ice cores, etc.) included in the database. The full database is available as a Microsoft Excel file as supplementary material for this paper (see text).

\begin{tabular}{|c|c|c|}
\hline Location & References & Type of data \\
\hline Dome B & Jouzel et al. (1995) & Ice core \\
\hline Vostok & $\begin{array}{l}\text { Vimeux et al. (2001) and Ekaykin et } \\
\text { al. (2002) }\end{array}$ & Ice core and snow pits + snowfall \\
\hline EPICA Dome C & Stenni et al. (2001) & Ice core \\
\hline Komsomolskaya & Ciais et al. (1994) & Ice core \\
\hline Taylor Dome & Steig et al. (1998) & Ice core \\
\hline Siple Dome & Brook et al. (2005) & Ice core \\
\hline Dome F & $\begin{array}{l}\text { Watanabe (1977), Satow (1977), Fujita } \\
\text { and Abe (2006), and Motoyama et } \\
\text { al. (2005) }\end{array}$ & Snow pit and precipitation \\
\hline \multirow[t]{2}{*}{ Law Dome } & Delmotte et al. (2000) & Firn cores \\
\hline & Masson-Delmotte et al. (2003) & Ice cores \\
\hline Dome A & This study & Firn core \\
\hline Byrd & This study & Ice core \\
\hline Dallinger Dome, James Ross Island & Aristarain et al. (2004) & 2 ice cores \\
\hline South Pole & Jouzel et al. (1983) & Firn core \\
\hline Vinson Massif & This study & Snowfall and fresh snow \\
\hline Caroline & Yao et al. (1990) & Ice core \\
\hline Mirny-Vostok 1985 Russian traverse & $\begin{array}{l}\text { Ekaykin et al. (2001) and Lipenkov et } \\
\text { al. (1998) }\end{array}$ & 29 pits \\
\hline $\begin{array}{l}\text { Terra Nova Bay-Dome C Italian } \\
\text { traverse, 1998-99 }\end{array}$ & $\begin{array}{l}\text { Stenni et al. (2000), Proposito et } \\
\text { al. }(2002) \text {, Frezzotti et al. (2005), and } \\
\text { this study }(\delta D)\end{array}$ & 107 pits \\
\hline $\begin{array}{l}\text { Terra Nova Bay-Dumont d'Urville } \\
\text { Italian traverse, 2001-02 }\end{array}$ & $\begin{array}{l}\text { Becagli et al. (2004), Magand et al. (2005) } \\
\text { and this study ( } \delta \mathrm{D})\end{array}$ & 108 pits \\
\hline Hercules Névé & Stenni et al. (1999) & Firn core \\
\hline Styx Glacier & Stenni et al. (2000) & Firn core \\
\hline Mc Carthy & Stenni et al. (2000) & Firn core \\
\hline Priestley Névé & Stenni et al. (2000) & Firn core \\
\hline Aviator Glacier & Stenni et al. (2000) & Snow pit \\
\hline Drygalski Glacier & Stenni et al. (2000) & Snow pit \\
\hline Victoria Land traverse 1998-99 & $\begin{array}{l}\text { Proposito et al. (2002) and Frezzotti et } \\
\text { al. (2005) }\end{array}$ & 7 snow pits \\
\hline Victoria Land traverse 2001-02 & $\begin{array}{l}\text { Becagli et al. (2004) and Magand et } \\
\text { al. (2005) }\end{array}$ & 8 snow pits \\
\hline \multirow{3}{*}{$\begin{array}{l}\text { Casey-Vostok, 1984; Dumont } \\
\text { d'Urville-Dome C 1994-95 and } \\
\text { 1995-96 French traverse }\end{array}$} & \multirow[t]{3}{*}{ Delmotte (1997) } & 17 pits \\
\hline & & 7 pits \\
\hline & & 5 pits \\
\hline \multirow{3}{*}{$\begin{array}{l}\text { Soviet, French, and Australian traverses } \\
\text { to Vostok and Dome B }\end{array}$} & \multirow[t]{3}{*}{ Petit et al. (1991) } & Dome B-Mirny: 12 pits \\
\hline & & 10 various pits $(\mathrm{BHF})$ \\
\hline & & 21 pits Mirny-Dome C \\
\hline $\begin{array}{l}\text { Erebus (1993 expedition of F. Le } \\
\quad \text { Guern) }\end{array}$ & This study & Fresh snow \\
\hline Estonian traverse to Dome B & This study & Pits \\
\hline Glacier Lambert Australian traverses & Delmotte (1997) & 134 pits \\
\hline Transantarctica & Dahe et al. (1994) & 104 pits \\
\hline Dumont d'Urville-Dome C, 1973 & Lorius and Merlivat (1977) & 48 pits \\
\hline Dumont d'Urville & This study & Snowfall (1-yr average) \\
\hline French pits in Adélie Land, 1982-83 & This study and Ciais (1991) & 32 pits \\
\hline Amery Ice Shelf & This study & Snow pit \\
\hline Chinese traverses to Dome A & Xiao et al. (2004) & 4 firn cores \\
\hline GC30 & Qin and Wang (1990) & 1 firn core \\
\hline W200 & Satow and Watanabe (1990) & 1 firn core \\
\hline Four IAEA GNIP stations & Rozanski et al. (1993) & Precipitation \\
\hline Berkner Island & Ruth et al. (2004) & 2 ice cores \\
\hline Campbell Glacier & Gragnani et al. (1998) & 3 firn cores \\
\hline Neumayer & Schlosser et al. (2004) & Precipitation monitoring \\
\hline Wilhelm Land & Smith et al. (2002) & 21 firn cores \\
\hline
\end{tabular}


TABLE 2. (Continued)

\begin{tabular}{|c|c|c|}
\hline Location & References & Type of data \\
\hline Talos Dome & Stenni et al. (2002) & 1 snow pit and 1 ice core \\
\hline Dominion Range & Mayewski et al. (1990) & Ice core \\
\hline Hercules Dome & Jacobel et al. (2005) & Ice core \\
\hline Dolleman Island & Peel (1992) & Ice core \\
\hline Dyer Plateau & Thompson et al. (1994) & Ice core \\
\hline Siple Station & Mosley-Thompson (1996) & Ice core \\
\hline Plateau remote & Mosley-Thompson (1996) & Ice core \\
\hline King George Island & Simões et al. (2004) & Ice core \\
\hline Frei Station & Simões et al. (2004) & Snowfall \\
\hline James Ross Island & Aristarain (1980) & Firn core \\
\hline Australian traverses & Morgan (1982) & 137 sampling sites (traverse pits) \\
\hline Dry Valleys & Gooseff et al. (2006) & 270 snow, pits, and ice cores \\
\hline U.S. West Antarctic ITASE & Steig et al. (2005) and this study & 11 firn cores \\
\hline Law Dome area & $\begin{array}{l}\text { V. Morgan (2007, personal } \\
\text { communication) }\end{array}$ & 22 firn cores \\
\hline Dronning Maud Land & $\begin{array}{l}\text { Isaksson and Karlén (1994) and Isaksson } \\
\text { et al. (1996, 1999) }\end{array}$ & 20 firn cores \\
\hline Dronning Maud Land AWS & Helsen $(2006)$ & 4 pits \\
\hline Foundation Ice Stream & Graf et al. (1999) & 16 firn cores \\
\hline EPICA Dronning Maud Land & Oerter et al. (2004) & 1 firn core and 1 ice core \\
\hline Dronning Maud Land area & This study & 15 snow pits \\
\hline Filchner-Ronne Ice Shelf & Graf et al. $(1994,1988)$ & 16 snow pits, 14 firn cores, and 3 ice cores \\
\hline Dronning Maud Land & Graf et al. (2002) & 27 firn cores \\
\hline Berkner Island & Wagenbach et al. (1994) & 2 shallow cores \\
\hline $\begin{array}{l}\text { Japanese Antarctic Research } \\
\text { Expedition (JARE) } 1977 \text { traverse }\end{array}$ & Kato et al. (1977) & 9 pits \\
\hline Druzhnaya & This study & 1 firn core \\
\hline Potsdam Gletscher & This study & 5 firn cores \\
\hline Ekströmisen, Ritscherflya & Oerter et al. (1999) & 8 snow pits and 9 firn cores \\
\hline Ritscherflya, Halvfarryggen, Sorasen & This study & 10 firn cores \\
\hline
\end{tabular}

values of each isotope. Annual mean surface air or firn temperatures are available for only 811 sites; the situation is even more restricted for annual mean accumulation data, available only for 322 sites (Fig. 2).

As seen in Figs. 2 and 3, the sampling is not evenly distributed within Antarctica. More than $82 \%$ of the sites are located in East Antarctica, and most of them are in the sector from $90^{\circ}$ to $180^{\circ} \mathrm{E}$ ( $64 \%$ of all sites). About $16 \%$ of the sites are located at an elevation below $1000 \mathrm{~m}$, and $42 \%$ of the sites are between 2000 and $3000 \mathrm{~m}$ above sea level (at latitudes between $75^{\circ}$ and $80^{\circ} \mathrm{S}$ ). Twenty-eight sites are located above $3500 \mathrm{~m}$. The range of estimated annual mean surface temperatures varies between $-3.2^{\circ}$ and $-59.2^{\circ} \mathrm{C}$.

\section{b. Quality control, data range, $\delta^{18} O-\delta D$ relationship}

For each location, the dataset was screened for quality control and a score was attributed, ranging from 0 (minimum quality control) to 5 (maximum quality control). The following five tests each contribute one point to the total score: (i) precise $\delta^{18} \mathrm{O}$ measurements (ana- lytical uncertainty of $0.1 \%$ or better), (ii) precise $\delta \mathrm{D}$ measurements (analytical uncertainty of $1.0 \%$ or better), (iii) number of measurements (at least 10 measurements combined to provide the statistics), (iv) age control on the sampling period (instead of just a core depth), and (v) seasonal resolution of the measurements. The first two criteria are expected to reflect the quality of the isotopic measurements and sample preservation; the last three criteria have been defined with respect to the temporal scale and resolution of the samples, with the purpose of building "climatologies" of surface snow isotopic composition.

We now describe the range of variability of $\delta \mathrm{D}, \delta^{18} \mathrm{O}$, and deuterium excess data, both spatially (from site to site) and temporally (within one site when several measurements have been averaged to produce the local average value). The full range of minimum and maximum $\delta \mathrm{D}$ measurements lies between $-491.5 \%$ ond $-46.0 \%$. The amplitude of local $\delta \mathrm{D}$ range (difference between maximum and minimum values of individual sample measurements at one location) varies between $4.9 \%$ o and $262.3 \%$, with a mean range of $74.1 \%$. This "dispersion" is not directly comparable from site to site be- 
a)
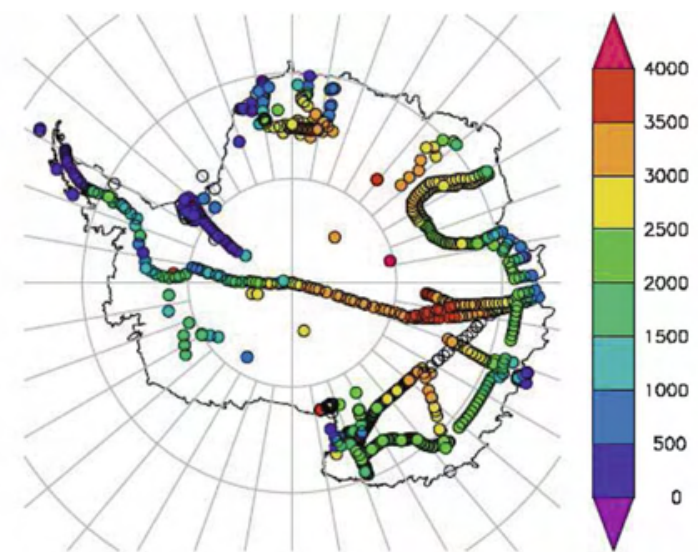

c)

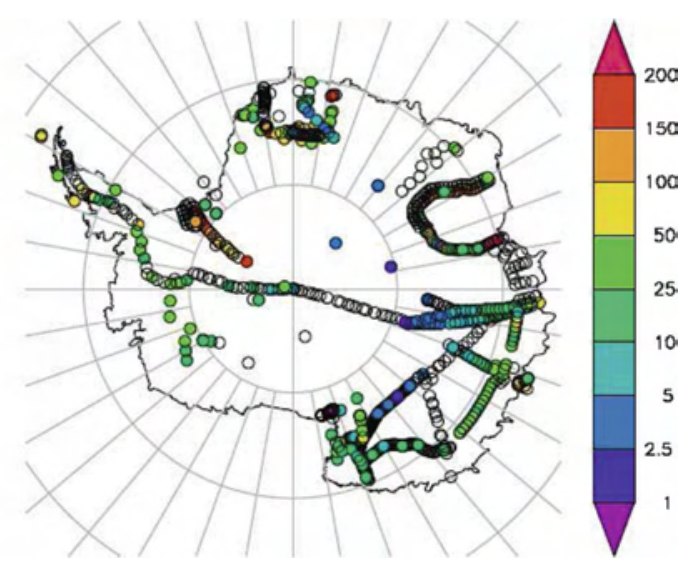

b)

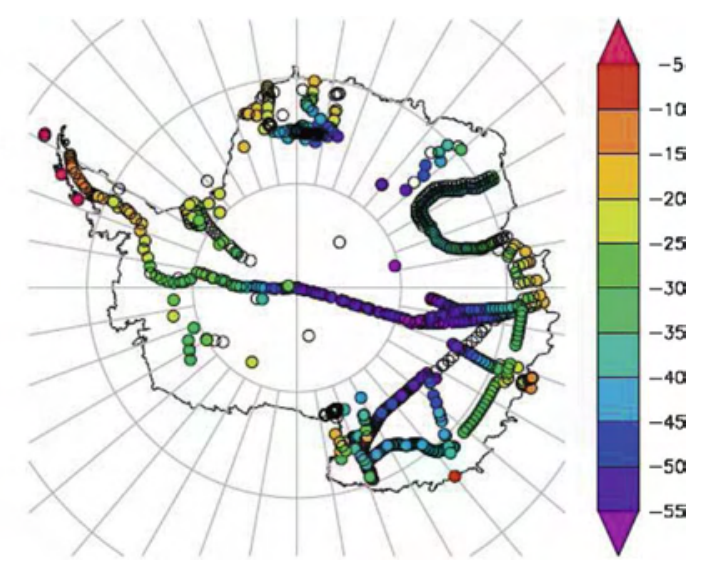

FIG. 2. Map of Antarctica showing (a) the elevation (m), (b) annual mean temperature $\left({ }^{\circ} \mathrm{C}\right)$, and (c) accumulation (in iceequivalent $\mathrm{cm} \mathrm{yr}^{-1}$ ) information available for the surface isotope data points. Empty circles correspond to areas where the displayed information is not available. cause of different sampling strategies (depth and/or time resolutions of the isotopic profiles). The largest range (typically up to $100 \%$ or more) probably corresponds to the magnitude of the seasonal cycle and/or individual storms producing widely varying isotopic values, as observed at the few locations where direct snowfall sampling has been performed. Despite the smoothing of the isotopic signals in the upper snow layers resulting from diffusion of water vapor, it seems that the detailed measurements conducted still capture part of the seasonal range. The standard deviation of $\delta \mathrm{D}$ measurements is on average $17 \%$, and often as low as $3 \%$ for low accumulation sites and as high as $53 \%$ for coastal sites. There is a small but significant tendency to have a linear correlation between the standard deviation and the mean $\delta \mathrm{D}$ values, probably due to the lower sampling resolution and diffusion of intraannual isotopic variability in inland locations. This standard deviation within each location remains small when compared with the range of the spatial distribution of average $\delta \mathrm{D}$ data (from $-72 \%$ o to $-454 \%$ ).

Similar results are observed for the $\delta^{18} \mathrm{O}$ database. The full range of $\delta^{18} \mathrm{O}$ measurements lies between $-63.7 \%$ and $-6.5 \%$; the local range at a single site varies between $0.8 \%$ and $33.2 \%$, with a mean value of $9 \%$. The local standard deviation is on average $2.4 \%$, but can be as high as $6.6 \%$. Similarly, this dispersion probably results from the interplay of temporal resolution of the data, diffusion, and seasonal/interannual precipitation isotopic composition variability. It is also small when compared to the spatial range of the average $\delta^{18} \mathrm{O}$ data (from $-9.5 \%$ to $-59.2 \%$ ).

The deuterium excess varies between $-15.4 \%$ and $28.9 \%$; the data range at each site varies between $0.8 \%$ o and $33.7 \%$, with a mean value of $7.8 \%$. The standard deviation is between $0.5 \%$ and $9.0 \%$, with a mean value of $2.2 \%$. There is a small tendency for a smaller dispersion at sites of high mean deuterium excess values, which may result from a reduced temporal resolution of local depth profiles and a larger effect of diffusion at low accumulation sites. Again, this local standard deviation remains small when compared to the full range of average deuterium excess values, from negative mean values in the Dry Valleys to $20 \%$ at high inland elevations.

An additional quality control test of both the quality of the sample preservation and the analytical accuracy lies in the observed relationship between $\delta \mathrm{D}$ and $\delta^{18} \mathrm{O}$ 
a)

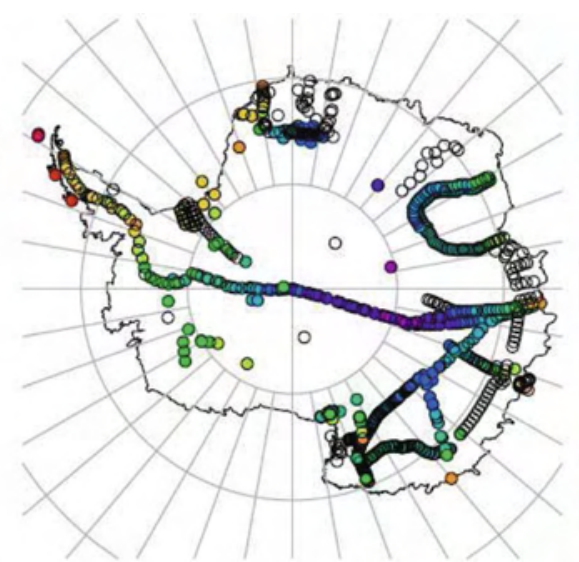

c)

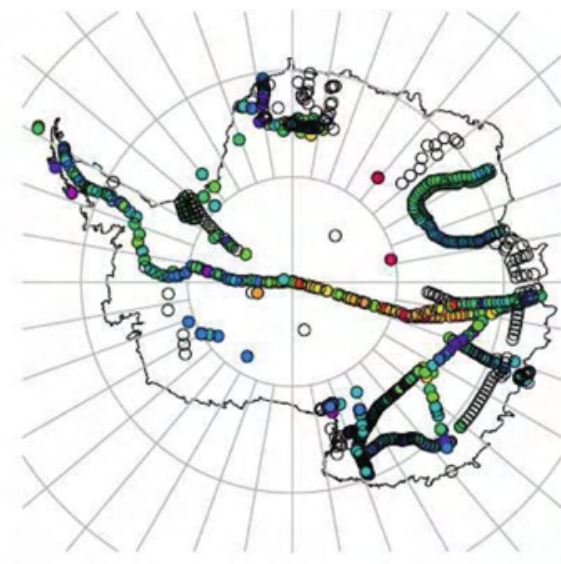

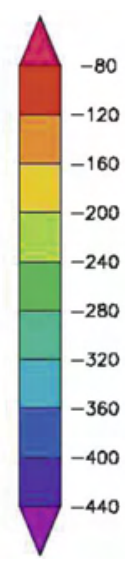

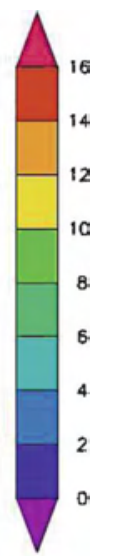

b)

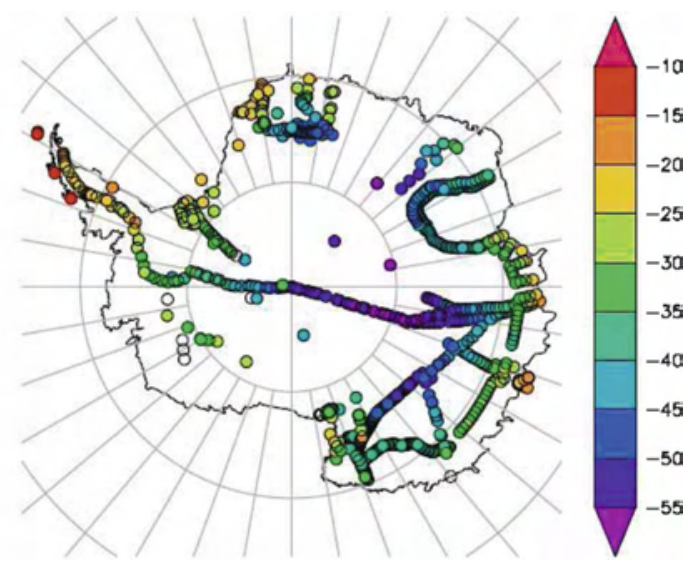

FIG. 3. Same as Fig. 1, but for (a) $\delta \mathrm{D}(\%)$, (b) $\delta^{18} \mathrm{O}(\%)$, and (c) deuterium excess (\%). Empty circles correspond to areas where the displayed information is not available.

(note again that for each site the average was calculated on all the individual isotopic data available, which is not necessarily the same for each isotope). As displayed in Fig. 4, the mean isotopic values for each database location are well aligned on a local meteoric water line, with a slope of $7.75 \pm 0.02 \%$ o $(\%)^{-1}\left(R^{2}=0.998, n=789\right)$. Several sites are characterized by negative deuterium

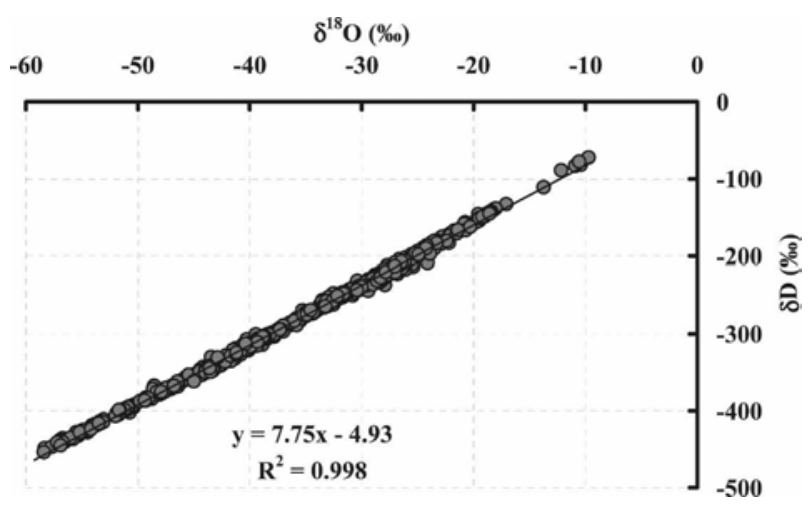

FIG. 4. Observed relationship between $\delta \mathrm{D}(\%)$ and $\delta^{18} \mathrm{O}(\%)$ for the entire dataset (789 points with both measurements available). The linear regression on the full dataset is displayed (black line). excess data, but still remain well aligned on the meteoric water line, which rules out any sample preservation problem.

\section{c. Factors controlling $\delta^{18} O$ and $\delta D$ spatial distribution}

\section{1) Geographical Factors}

The continental distribution of $\delta \mathrm{D}$ and $\delta^{18} \mathrm{O}$ is displayed on Fig. 3. Geographical factors control their distribution, such as the shortest distance to the coast, latitude, and elevation. A study of the linear relationships between geographical parameters and isotopic data (Table 3) makes it possible to propose multiple linear regression models, which account for $85 \%$ of the $\delta \mathrm{D}$ and $88 \%$ of the $\delta^{18} \mathrm{O}$ spatial variance:

$$
\begin{aligned}
\delta \mathrm{D} & =944.460 \times \sin (\lambda)-0.057 \times H-0.0034 \times D \\
(n & \left.=568, \quad R^{2}=0.85\right),
\end{aligned}
$$

with $\delta \mathrm{D}$ in $\%, \lambda$ the latitude, $H$ the elevation (m), and $D$ the distance to the nearest coast (including ice shelves; $\mathrm{km}$ ),

$$
\delta^{18} \mathrm{O}=944.460 \times \sin (\lambda)-0.057 \times H-0.0034 \times D .
$$


TABLE 3. Study of correlations between surface isotopic distribution and geographical variables: (a) single linear relationships (correlation coefficients displayed only when significant with a confidence level of $99.9 \% ; \times$ means no correlation). The sine of the latitude is used. The single correlations are analyzed on subsets of data for which the records are available. Correlations used for multiple regressions are in bold. (b) Multiple linear model to estimate $\delta \mathrm{D}$ and $\delta^{18} \mathrm{O}$ as a function of the sine of the latitude, altitude, and distance from coast. The analyses are conducted on the subsets of data for which all of these data are available (the number of points $\mathrm{n}$ is displayed), leading to slightly different results when compared to (a). Results are displayed in terms of slope, regression coefficient, and percentage of the reconstruction variance explained by each of the two to three predictants.

(a)

\begin{tabular}{|c|c|c|c|c|c|c|c|c|c|}
\hline & $\begin{array}{c}\text { Sine of } \\
\text { latitude }\left(^{\circ}\right)\end{array}$ & $\begin{array}{l}\text { Longitude } \\
\quad\left(^{\circ}\right)\end{array}$ & $\begin{array}{l}\text { Altitude } \\
\text { (m) }\end{array}$ & $\begin{array}{l}\text { Distance } \\
(\mathrm{km})\end{array}$ & $\begin{array}{l}\text { Temperature } \\
\left({ }^{\circ} \mathrm{C}\right)\end{array}$ & $\begin{array}{l}\text { Accumulation } \\
\left(\mathrm{cm} \mathrm{yr}^{-1}\right)\end{array}$ & $\begin{array}{l}\delta \mathrm{D} \\
(\% \mathrm{o})\end{array}$ & $\begin{array}{l}\delta^{18} \mathrm{O} \\
(\%)\end{array}$ & $\begin{array}{c}\text { Excess } \\
(\% \mathrm{o})\end{array}$ \\
\hline Sine of latitude & 1.00 & $x$ & $\times$ & -0.49 & 0.62 & 0.69 & 0.74 & 0.68 & $\times$ \\
\hline Longitude $\left(^{\circ}\right)$ & & 1.00 & 0.40 & $\times$ & -0.51 & $\times$ & $x$ & $x$ & $\times$ \\
\hline Altitude (m) & & & 1.00 & 0.66 & -0.90 & -0.32 & -0.87 & -0.87 & 0.47 \\
\hline Distance $(\mathrm{km})$ & & & & 1.00 & -0.75 & $\times$ & -0.75 & -0.77 & 0.65 \\
\hline Temperature $\left({ }^{\circ} \mathrm{C}\right)$ & & & & & 1.00 & $\times$ & 0.95 & 0.96 & -0.44 \\
\hline Accumulation $\left(\mathrm{cm} \mathrm{yr}^{-1}\right)$ & & & & & & 1.00 & $x$ & $\times$ & $\times$ \\
\hline$\delta \mathrm{D}(\% \mathrm{o})$ & & & & & & & 1.00 & 1.00 & -0.52 \\
\hline$\delta^{18} \mathrm{O}(\%)$ & & & & & & & & 1.00 & -0.56 \\
\hline Excess $(\%)$ & & & & & & & & & 1.00 \\
\hline
\end{tabular}

(b)

\begin{tabular}{|c|c|c|c|c|c|c|c|c|c|}
\hline & \multicolumn{3}{|c|}{$\delta \mathrm{D}(\%), n=561$} & \multicolumn{3}{|c|}{$\delta^{18} \mathrm{O}(\%), n=747$} & \multicolumn{3}{|c|}{$\begin{array}{c}\text { Excess (\%o) } \\
(\text { above } 2000 \mathrm{~m}), n=413\end{array}$} \\
\hline & Slope & $R$ & $\%$ & Slope & $R$ & $\%$ & Slope & $R$ & $\%$ \\
\hline Sine of latitude & 944.46 & 0.60 & 20 & 151.59 & 0.62 & 24 & & & \\
\hline Altitude (m) & -0.057 & -0.85 & 66 & -0.007 & -0.87 & 66 & 0.004 & 0.76 & 58 \\
\hline Distance from coast $(\mathrm{km})$ & -0.034 & -0.75 & 14 & -0.003 & -0.79 & 10 & 0.004 & 0.73 & 42 \\
\hline Reconstructed series & & 0.92 & & & 0.95 & & & 0.80 & \\
\hline
\end{tabular}

In this linear analysis, the site elevation appears as the first driver for $\delta \mathrm{D}$ and $\delta^{18} \mathrm{O}$ spatial variations. The impact of elevation on isotopic values is particularly striking for mountain ranges, and this paper includes isotopic measurements from the highest Antarctic location, Mount Vinson Massif. The multiple linear regression models can be used to map the spatial distribution of $\delta \mathrm{D}$ and $\delta^{18} \mathrm{O}$ expected from geographical features, based on Antarctic topographic data (Huybrechts et al. 2000). Such geographical regressions may be useful for the forcing of Antarctic ice sheet models using isotopic tracers (Lhomme et al. 2005).

Anomalies between the observed and modeled mean isotopic ratios have been analyzed (not shown). The standard deviation of the anomalies remains limited (3.1\% for $\delta^{18} \mathrm{O}$ and $27 \%$ for $\delta \mathrm{D}$ ), and the maximum deviation is $14 \%$ for $\delta^{18} \mathrm{O}$ and $107 \%$ for $\delta \mathrm{D}$. The observations show isotopic values that are less depleted than the calculation (positive anomalies) on the flanks of the ice sheet (at elevations from 1000 to $2000 \mathrm{~m}$ ) and inland West Antarctica, whereas they show isotopic values that are more depleted than the calculation (negative anomalies) in the central Antarctic Peninsula and the central East Antarctic plateau.

Different moisture origins and transportation paths may account for these regional peculiarities. Isotopic values for the interior sites of the East Antarctic ice divide between Dome A and Dome $\mathrm{C}$ are more negative than those for the flanks facing the Southern Ocean (Dahe et al. 1994; Proposito et al. 2002; Magand et al. 2005). The most depleted surface snow isotopic values ( $\delta \mathrm{D}$ of $-453.7 \%$ and $\delta^{18} \mathrm{O}$ of $-58.4 \%$ ) have been surveyed $70 \mathrm{~km}$ south of Vostok (Dahe et al. 1994) at an elevation of $3430 \mathrm{~m}$ and $1245 \mathrm{~km}$ from the coast, whereas the first firn core recovered at the highest and probably coldest point of East Antarctica (Dome A, $4039 \mathrm{~m}, 1180 \mathrm{~km}$ inland) exhibits slightly less depleted isotopic values ( $\delta \mathrm{D}$ of $-448.4 \%$ and $\delta^{18} \mathrm{O}$ of $-58.32 \%$ ).

The same situation has been observed along the traverse from Dome C to Terra Nova Bay, where isotopic values are relatively more depleted on the Ross Sea side (at lower elevations) than on the Southern Ocean side (Magand et al. 2005). Backward air parcel trajectories and snow accumulation distribution reveal that the snowfall trajectories at Vostok and Dome C originate on the Southern Ocean side (Reijmer et al. 2002; Urbini et al. 2008). This example from the area with the most intense isotopic depletion highlights regional impacts of moisture history and origin on isotopic values. 
Another example of the influence of moisture trajectory on the spatial distribution of surface snow isotopic composition arises from the documentation of isotopic variability on the flanks of Law Dome. In this location, it is not the distance from the coast or the elevation that are the main drivers of isotopic depletion, but the distribution along an east-west transect, because moisture is advected from southeast cyclonic activity (Simmonds and Keay 2000). In this case, the east-west gradient of isotopic depletion is associated with a gradient of accumulation, linked to an orographic shadow effect on air masses that cross the ice divide (Morgan 1982; Morgan et al. 1997).

In the comparison between modeled isotopic composition and field measurements (not shown), difficulties may arise from local effects such as moisture paths (described previously). Postdepositional processes may induce systematic effects on isotopic values resulting from either wind-driven ablation (scouring) effects on the flanks of the ice sheet where local topography can be complex (Ekaykin et al. 2002; Frezzotti et al. 2004, 2007) or sublimation effects in the dry areas (Neumann and Waddington 2004).

\section{2) Relationship With TEMPERATURE}

The spatial variations of $\delta \mathrm{D}$ and $\delta^{18} \mathrm{O}$ are strongly related to the spatial variation of temperature, which is strongly related to the distance from the open ocean ("continentality effect"), latitude (link with insolation), elevation (vertical lapse-rate effect), and atmospheric circulation (penetration of synoptic cyclonic systems). In the database [using automatic weather station (AWS) or firn temperature measurements], a spatial temperature gradient of $-11.4^{\circ} \pm 0.2^{\circ} \mathrm{C}(1000 \mathrm{~m})^{-1}$ elevation is observed, together with a temperature decrease of $-27.8 \pm 0.9^{\circ} \mathrm{C}(1000 \mathrm{~km})^{-1}$ from the coast. Spatial surface temperature/elevation slopes may vary between $9^{\circ}$ (coastal areas) and $12^{\circ} \mathrm{C}(1000 \mathrm{~m})^{-1}$ (sectors of the central plateau).

The database makes the study of the isotopetemperature slopes possible (Figs. 5 and 6a,b). Such relationships have classically been used to estimate past temperatures from Antarctic ice cores, starting with the pioneering work of Lorius and Merlivat (1977). A significant $(p<0.01)$ linear regression is obtained from the whole database (Fig. 6), with a slope of $0.80 \% \pm$ $0.01 \%$ o $\left({ }^{\circ} \mathrm{C}\right)^{-1}(n=745)$ for $\delta^{18} \mathrm{O}$ and $6.34 \%$ o $\pm 0.09 \%$ $\left({ }^{\circ} \mathrm{C}\right)^{-1}$ for $\delta \mathrm{D}(n=547)$. The uncertainties on the linear slopes have been obtained by using a Monte Carlo method applied on 1000 randomly selected subsets of the database (subset size of 500 samples with possible multiple random selection of the same data). For $\delta \mathrm{D}$, the slope is in good agreement with earlier estimates conducted on subsets of the data (Lorius and Merlivat 1977; Dahe et al. 1994); for $\delta^{18} \mathrm{O}$, it appears to be slightly larger than the first estimates, which were closer to $0.75 \%$ o $\left({ }^{\circ} \mathrm{C}\right)^{-1}$ (Dansgaard et al. 1973; Lorius and Merlivat 1977).

Observed isotope-temperature slopes vary depending on the location of the sites. To assess the spatial variations of this slope, we have developed a methodology to estimate local slopes. For each data point, we have selected the closest (up to 200) points located within $400 \mathrm{~km}$ thereof, and calculated the spatial slopes from these neighbors. This radius was selected to obtain a minimum number of data points to assess correlation coefficients, and it is a compromise between a more limited radius (more closely representative of single topographic features) and a wider radius (losing track of regional features, but constructing slopes based on more numerous data). The methodology used for calculating local slopes does not take into account topography, and therefore combines data from different drainage basins and moisture source areas. It is suggested that areas associated with small correlation coefficients may reflect boundaries between different moisture advection paths.

Figure 5 displays the results obtained for local correlation coefficients that are greater than 0.5 . We observe that slopes may vary locally by $20 \%$ or more. Smaller-than-average isotope-temperature slopes are observed in the central part of West Antarctica, in East Antarctica between Casey and Vostok, and in areas of Dronning Maud Land. Larger-than-average isotopetemperature slopes are observed in some coastal areas on the west side of the Lambert Glacier basin and in areas of the East Antarctic plateau. There is no clear relationship between the local slopes and the latitude or longitude of the sites. In Fig. 5, the slopes near Dome C, Vostok, or other ice divides have not been plotted because they show a local correlation coefficient less than 0.5 , but isotope transects from Dumont d'Urville or Terra Nova Bay to Dome C exhibit a coherence of data much larger than 0.5 .

The Lambert Glacier basin (Delmotte 1997) is an area where the number of data locations (71) makes the determination of the local isotope-temperature relationships possible. Systematic differences between isotopic values are observed in the west and east sides of the basin, which are almost fully explained by the differences in elevation and temperature and our linear model (Table 3). Larger $\delta \mathrm{D}$-temperature slopes are observed on the west side $\left(+6.80 \% \pm 0.57 \%\right.$ o $\left({ }^{\circ} \mathrm{C}\right)^{-1}, R=$ $0.85)$ than on the east side $\left(+5.56 \% \pm 0.51 \%\right.$ o $\left({ }^{\circ} \mathrm{C}\right)^{-1}$, $R=0.88$ ). Local deviations up to $20 \%$ from the mean isotope-temperature slope are observed in the Lambert 

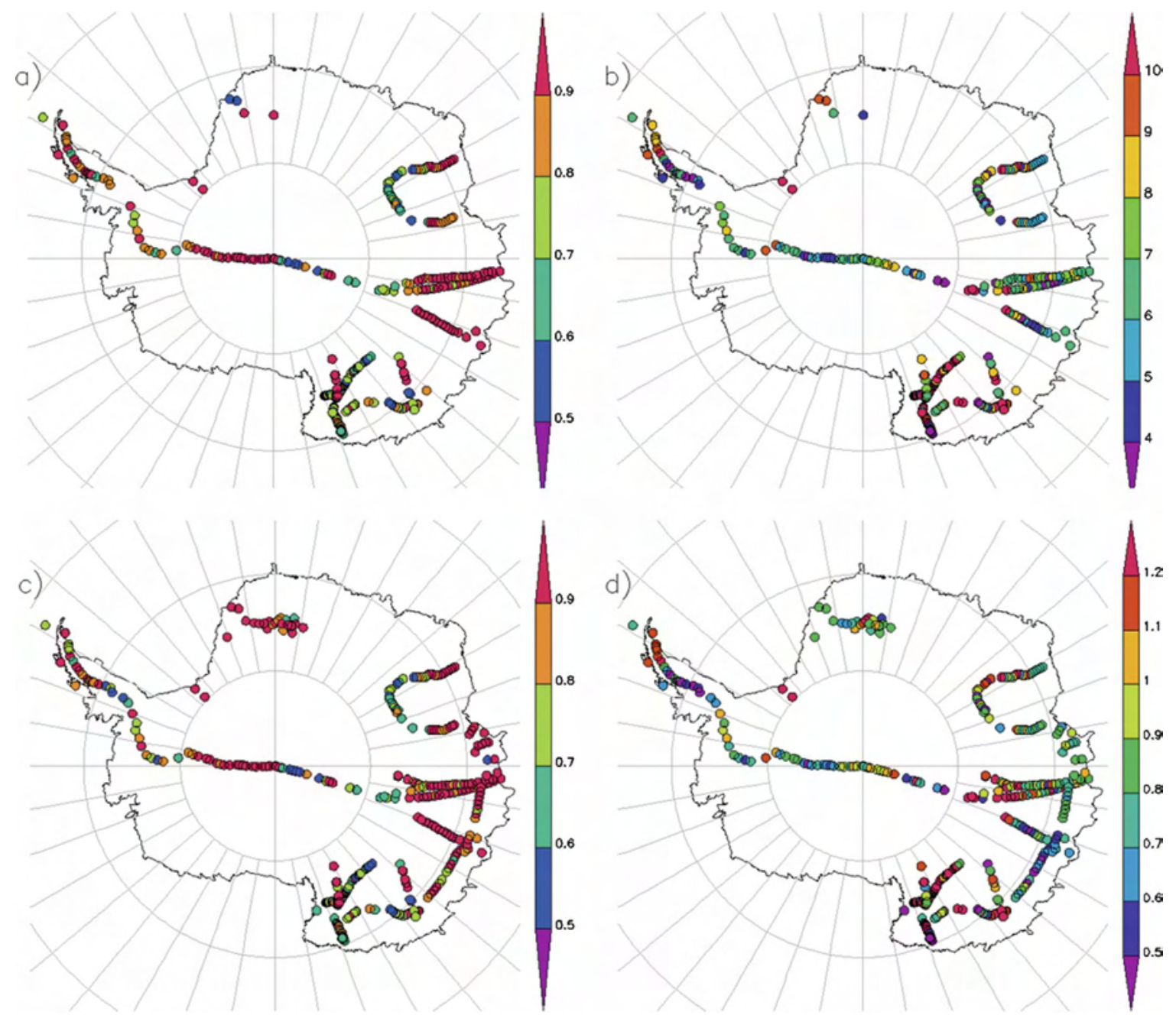

FIG. 5. Local linear regression analysis is shown for the relationship between surface temperature and surface snow $\delta \mathrm{D}$ and $\delta^{18} \mathrm{O}$. For each point, a search was conducted over the nearest 200 points of the database, within a maximum distance of $400 \mathrm{~km}$ : (a) local correlation coefficient between temperature and $\delta \mathrm{D},(\mathrm{b})$ local $\delta \mathrm{D}-$ temperature slope $\left[\%\left({ }^{\circ} \mathrm{C}\right)^{-1}\right]$, (c) local correlation coefficient between temperature and $\delta^{18} \mathrm{O}$, and (d) local $\delta^{18} \mathrm{O}$-temperature slope $\left[\% \circ\left({ }^{\circ} \mathrm{C}\right)^{-1}\right]$.

Glacier area, again pointing to a $20 \%$ uncertainty in the application of regional transfer functions for local studies. For this specific area, seasonal deposition and/or snow erosion may influence the mean isotopic composition. The systematic differences in mean isotopetemperature slopes and deuterium excess (see next section) may also result from different moisture origins on the two flanks of the Lambert Glacier.

The Dome C drainage area, where there have been several surveys, is characterized by a high local variability of temperature, snow accumulation, and $\delta^{18} \mathrm{O}$ data, with isotope-temperature slopes varying from $0.60 \%$ to $0.91 \%$ o $\left({ }^{\circ} \mathrm{C}\right)^{-1}$ and route-dependent slopes (with distinct patterns on north-south and east-west transects) (Magand et al. 2005). These local differences have been shown to arise first from depositional effects (different moisture origins and trajectories), and second from postdepositional effects, with a large role played by katabatic wind patterns. Regional slopes along the flanks of the ice sheet may be associated with wind-driven sublimation phenomena (controlled by the surface slope along prevailing wind directions), less penetration of the synoptic cyclonic system (correlated with persistence of higher pressure in katabatic wind areas), and isotopic depletion in precipitation induced by an orographic "shadowing" effect of the air mass that crosses the ice divide, as suggested by Frezzotti et al. (2004), Magand et al. (2005), and Frezzotti et al. (2007) from traverses between Terra Nova Bay, Dome C, and Talos Dome.

One can examine the temporal stability of these spatial isotope-temperature slopes. Repeated traverses 
(a)

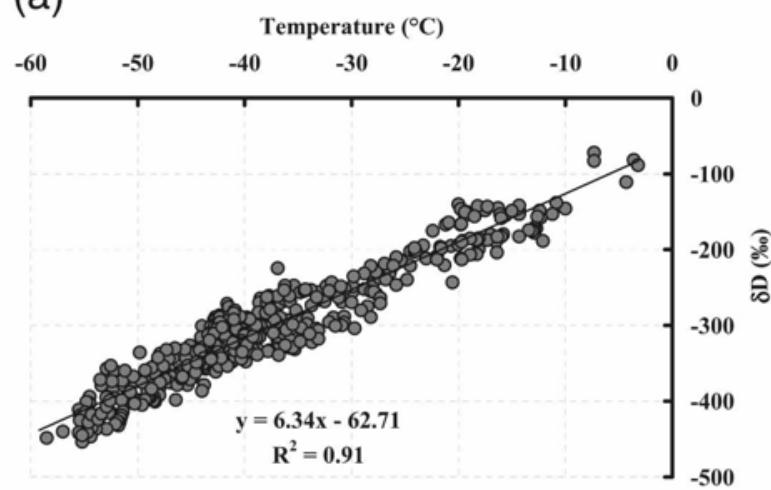

(c)

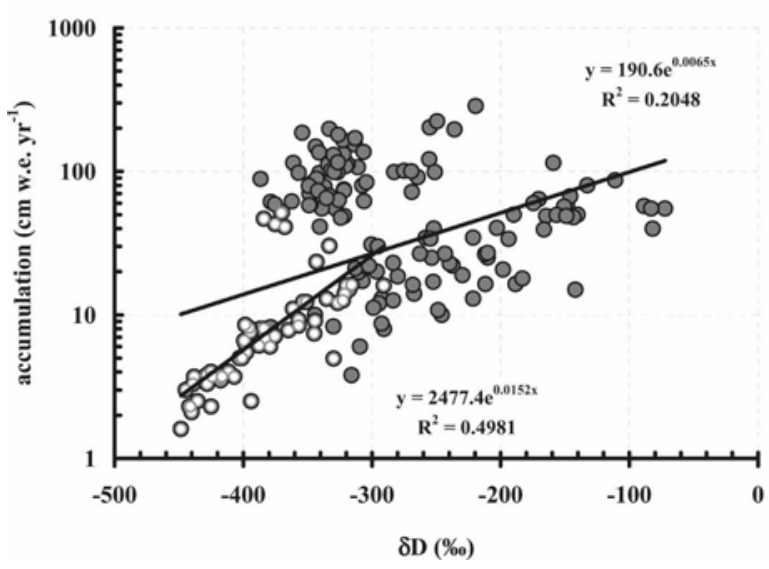

(e)

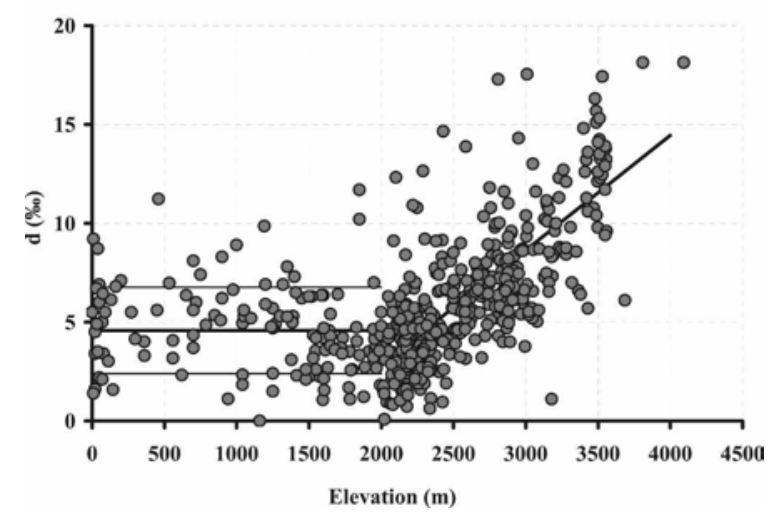

conducted between Dumont d'Urville and Dome C make the comparison possible of spatial gradients observed both during the first traverses (1971-73) (Lorius and Merlivat 1977) and during the initial traverses associated with the construction of the Concordia station (1995-96). The temperature data were obtained from 10-m firn measurements for the first traverse, and from AWS data for the second one. The difference between the two $\delta \mathrm{D}$ datasets is within the natural variability, around $10 \%$. When considering the sites in a similar range of elevation and temperature (excluding coastal (b)

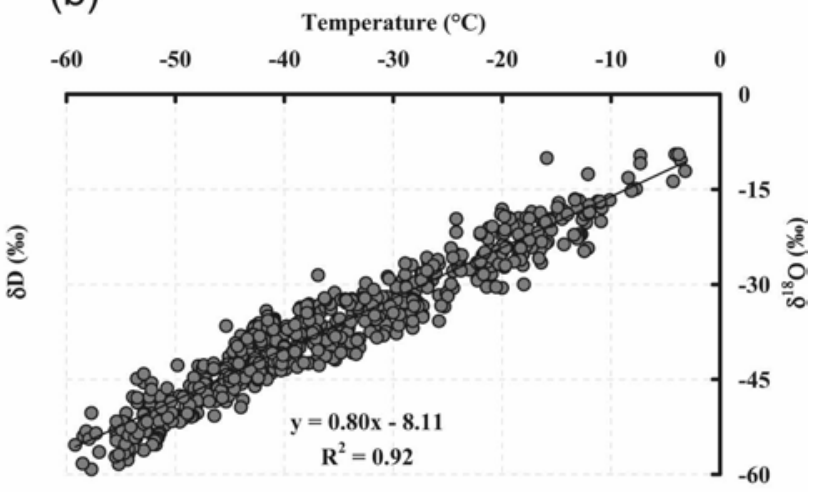

(d)

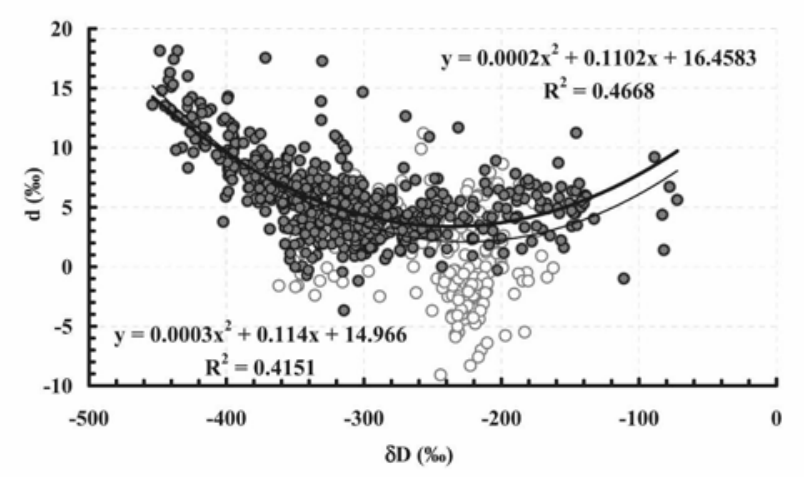

FIG. 6. Relationships between (a) surface temperature $\left({ }^{\circ} \mathrm{C}\right)$ and $\delta \mathrm{D}(\%)$, (b) surface temperature $\left({ }^{\circ} \mathrm{C}\right)$ and $\delta^{18} \mathrm{O}(\%)$, (c) $\delta \mathrm{D}(\%)$ and accumulation (water-equivalent $\mathrm{cm} \mathrm{yr}^{-1}$; white circles, data points restricted to elevations above $2754 \mathrm{~m}$ ), and (d) surface $\delta \mathrm{D}$ (\%) and deuterium excess (\%) are shown. The Dry Valleys data are highlighted as white circles. Two quadratic regressions have been conducted: one on the full dataset (thin line, bottom formula) and one on the dataset without the Dry Valleys data (thick line, top formula). (e) Relationship between elevation (m) and deuterium excess (\%) is also shown. For elevations below $2000 \mathrm{~m}$, the black lines represent the average value, plus or minus one std dev; for elevations above $2000 \mathrm{~m}$, the black line is the best linear fit to the data $\left[R^{2}=0.54\right.$, slope $\left.=5.8 \%(1000 \mathrm{~m})^{-1}\right]$.

locations at temperatures above $-35^{\circ} \mathrm{C}$ and the Dome $\mathrm{C}$ area), the spatial $\delta \mathrm{D}$-temperature gradients are $6.73 \%$ o $\pm 0.37 \%$ o $\left({ }^{\circ} \mathrm{C}\right)^{-1}(n=25, R=0.97)$ for the samples collected in $1971-73$ and $6.70 \% \pm 0.58 \%$ $\left({ }^{\circ} \mathrm{C}\right)^{-1}(n=10, R=0.97)$ for the samples collected in 1995-96 (Delmotte 1997).

Although restricted to a single route in Antarctica, this result suggests a remarkable stability of the isotopetemperature slope over a time period of $20-25 \mathrm{yr}$, despite indications of significant trends in some Antarctic winter tropospheric temperature records (Turner 
et al. 2006). Repeated traverse measurements in a climate change context may provide comparisons of the spatial and temporal slopes; our dataset does not make it possible to assess temporal slopes resulting from the temporal stability of local temperatures and isotopic values, at least in central Antarctica.

For the 25th percentile of sites with the highest elevations (above $2754 \mathrm{~m}$ ), the observed $\delta \mathrm{D}$-temperature slope is $7.1 \%$ o $\pm 0.4 \%$ o $\left(n=134, R^{2}=0.7\right)(0.85 \%$ o \pm $0.04 \% ; n=175, R^{2}=0.7$ for $\left.\delta^{18} \mathrm{O}\right)$, and reaches $9.1 \%$ o $\pm 0.7 \%$ o $\left({ }^{\circ} \mathrm{C}\right)^{-1}\left(R^{2}=0.7\right)$ for the 39 sites above $3300 \mathrm{~m}$ of altitude $\left(0.94 \%\right.$ o $\pm 0.09 \%, n=57, R^{2}=0.5$ for $\left.\delta^{18} \mathrm{O}\right)$. On the central Antarctic plateau, the spatial slope is significantly larger (by $15 \%-35 \%$ ) than the slope obtained for the full dataset. The regional changes in the isotope-temperature slope are large contributors to the $20 \%-30 \%$ uncertainty of past Antarctic temperature reconstructions based on stable isotopes of water (Jouzel et al. 2003).

\section{3) Relationship With acCumulation}

The relationship between stable isotopes and accumulation forms the basis for the dating of deep ice cores, through the modeling of accumulation and ice thinning. Inverse glaciological dating methods applied for Vostok, Dome Fuji, EPICA DML, and EPICA DC use age control points to infer parameters controlling an exponential relationship between accumulation and ice $\delta \mathrm{D}$ content, which is assumed to arise from the thermodynamics of moist air through the saturation vapor pressure (Jouzel et al. 1987a; Parrenin et al. 2001; Watanabe et al. 2003; EPICA Community Members 2004; Parrenin et al. 2004; EPICA Community Members 2006).

Figure $6 c$ displays the observed relationship between $\delta \mathrm{D}$ and the accumulation for all of the 171 points where both data are available (Magand et al. 2005), and for the points above $2754-\mathrm{m}$ elevation (25th percentile of the elevation distribution for all the $\delta \mathrm{D}$ data sites, hereafter considered "high-elevation sites"). It must be noted that the accumulation estimates rely on different methods for the various sites, and may be obtained on time periods that are different from the time period used for the averaging of the isotopic values. Because of the different methods used for each location, we were not able to quantitatively assess the uncertainty. Exponential fits are obtained in both cases, but with significantly different coefficients. The best fit is clearly not linear, as previously shown by linear regressions (Table 3 ). This result suggests that the accumulation-isotope relationships observed today for the cold conditions of the central plateau may not be extrapolated to warmer conditions, a result that has implications for the mod- eling of the accumulation used for ice core dating (Monnin et al. 2004).

In the range of $\delta \mathrm{D}$ values from $-300 \%$ to $-350 \%$, corresponding to elevations from 1500 to $2500 \mathrm{~m}$, a large range of accumulation values is found, probably resulting from wind-driven postdepositional effects on the slopes leading to the Antarctic Plateau (Frezzotti et al. 2004; Frezzotti et al. 2005). The best exponential fit $\left(A=A_{0} e^{\beta \delta \mathrm{D}}\right)$ is obtained at high elevations $\left(R^{2}=0.5\right)$, with $\beta=0.0152 \%^{-1}$. Interestingly, this coefficient is very similar to the coefficient used for the optimal dating of the EPICA DC ice core (Parrenin et al. 2007) $(\beta=0.0157)$, suggesting that similar atmospheric processes control the relationship between ice $\delta \mathrm{D}$ and accumulation for their spatial distribution today and for their past variations at Dome C.

\section{d. Factors controlling the deuterium excess spatial distribution}

The primary geographical factors controlling deuterium excess spatial distribution in Antarctica appear to be both elevation and distance from the coast (Table 3 ). However, a linear model fails to produce a satisfying representation of deuterium excess at low-elevation sites. Therefore, the regression has been restricted to locations above 2000-m elevation and accounts for $64 \%$ of the spatial variance of deuterium excess. In this case, a linear model can be used to estimate the spatial distribution of deuterium excess of surface snow using Antarctic topography data (Huybrechts et al. 2000; not shown).

The limited performance of the linear regression model for deuterium excess in West Antarctica and coastal locations may result from either the limited set of deuterium excess observations and their uncertainties, or factors other than elevation and distance from the coast controlling this parameter. In particular, it is possible that geographical differences in moisture origin could be responsible for regional features of the real deuterium excess distribution (Simmonds et al. 2003). Obtaining a better spatial coverage in these areas could make the identification of such moisture origin effects possible.

Earlier compilations of deuterium excess data (Petit et al. 1991; Dahe et al. 1994) had used the range of variability of deuterium excess measured along pits from Vostok to expand the range of observed values. In the new data compiled for this database, Dome Fuji and Dome A exhibit the highest mean deuterium excess values, at $18.1 \%$. The spatial distribution of deuterium excess data is improved both at such high-elevation sites and also in coastal areas.

A number of samples of fresh snow or surface snow 
exhibit negative deuterium excess data, such as about eight samples from traverses (Dahe et al. 1994; Frezzotti et al. 2005), several samples from Vostok precipitation (Ekaykin et al. 2001; Ekaykin 2003), and many samples from the Dry Valleys (Gooseff et al. 2006). These data were scrutinized for the observed $\delta \mathrm{D}-\delta^{18} \mathrm{O}$ slope (Fig. 4), but exhibit no deviation from the Antarctic meteoric water line.

Only a few studies have been dedicated to the study of postdepositional effects on Antarctic snow deuterium excess. The work by Satake and Kawada (1997) suggested that the depth of hoar formation and sublimation may increase deuterium excess values, whereas other studies (Neumann and Waddington 2004; Neumann et al. 2005) suggested that mass loss during firn metamorphism could induce deuterium excess decreases at low-accumulation sites. Because all of the sites with negative deuterium excess values are located at elevations lower than $2400 \mathrm{~m}$, it is suggested that wind ablation effects may reduce accumulation and increase the residence time of snow crystals in the surface zone characterized by strong temperature gradients. This temperature gradient is expected to induce moisture movements in the firn and could induce isotopic fractionation.

The distribution of deuterium excess as a function of $\delta \mathrm{D}$ (Fig. 6d) now relies on 789 data points, including new traverse data available from the coast to the interior of East Antarctica and 269 data points from the Taylor Valley in the Dry Valleys (with many negative deuterium excess values). Because the spatial distribution of deuterium excess versus $\delta \mathrm{D}$ is often used for model-data comparisons (see section 3), we have calculated the best fit of this distribution for all of the points and for all of the points outside of the Dry Valleys. The shape of the polynomial fit remains essentially the same for the inland data, but is slightly modified for $\delta \mathrm{D}$ values above $-300 \%$. In fact, the shape of the relationship remains poorly constrained around the coasts of Antarctica (for $\delta \mathrm{D}$ values above $-150 \%$ ), where only a few data from IAEA GNIP stations data are available. However, the relationship appears to be parabolic as suggested earlier by Petit et al. (1991) and Delmotte (1997), with a wide deuterium excess minimum for $\delta \mathrm{D}$ values above $-250 \%$, in contrast to the shape of the best fit obtained by Dahe et al. (1994).

A significant negative spatial correlation between surface temperature and deuterium excess is observed (Table 3), corresponding also to the negative correlation between deuterium excess versus $\delta \mathrm{D}$ (Fig. $6 \mathrm{~d}$ ). The following several processes are invoked to account for this negative correlation: (i) changes in equilibrium fractionation coefficients at low temperatures with an impact on the actual $\delta \mathrm{D}-\delta^{18} \mathrm{O}$ slope, a smaller depletion of $\delta \mathrm{D}$ compared to $8 \times \delta^{18} \mathrm{O}$, and consequently an increase of deuterium excess along the distillation path; (ii) the role of kinetic fractionation at supersaturation on ice crystals (Jouzel and Merlivat 1984); and (iii) changes in moisture origin. Simulations conducted with isotopic models allow us to assess the relative importance of these different processes (section 3).

In the Lambert Glacier area, deuterium excess values are on average $6.5 \%$ on the west side, compared to $3.8 \%$ on the east side. Because of the elevation effect, higher deuterium excess values are expected on the higher-elevation side of the glacier. The west/east side anomalies regarding isotope-temperature slopes (previous section) and deuterium excess values suggest that different depositional or postdepositional processes take place on both sides of the Lambert Glacier (Delmotte 1997). Local meteorological conditions may be associated with different trajectories of moisture transport as well as different erosion mechanisms (Xiao et al. 2001).

The most striking result in terms of the distribution of deuterium excess data is the shape of its dependence on elevation (Fig. 6e). The marked difference at elevations below versus above $2000 \mathrm{~m}$ suggests that different moisture origins may account for the observed deuterium excess shifts; a dominant supply of moisture is provided by "cold" high-latitude ocean sources toward coastal locations, and the progressive input of moisture provided by more remote sources, transported at high elevations into central Antarctica, has undergone a different distillation path with a stronger influence of kinetic effects. Atmospheric models can be used to analyze the vertical moisture advection to Antarctica (see section 3) and test this hypothesis.

The observed deuterium excess spatial distribution also reflects changes in the $\delta \mathrm{D}-\delta^{18} \mathrm{O}$ slope depending on the range of isotopic values (Fig. 4). The first quartile of the $\delta^{18} \mathrm{O}$ distribution $\left(\delta^{18} \mathrm{O}\right.$ values above $-30.4 \%$ ) exhibits a slope of $8.37 \%$ o $\pm 0.06 \%$ o $(\%)^{-1}$ $\left(R^{2}=0.987 ; n=198\right)$, whereas it is $7.28 \% \pm 0.05 \%$ o $(\%)^{-1}\left(R^{2}=0.993 ; n=198\right)$ for the last quartile of the $\delta^{18} \mathrm{O}$ distribution $\left(\delta^{18} \mathrm{O}\right.$ values below $-42.8 \%$ ). These slope uncertainties have been obtained from a Monte Carlo method using 1000 random subsets. Confirming earlier studies (Vimeux et al. 1999), we show here that the $\delta \mathrm{D}-\delta^{18} \mathrm{O}$ slopes decrease from coastal to inland Antarctica. Theoretical isotopic models indeed simulate a lower slope at colder temperatures as a result of the imprint of condensation temperature on the ratio of the deuterium and oxygen-18 equilibrium fractionation coefficients. During glacial periods, slopes below 
$7.30 \%$ o $(\%)^{-1}$ are observed in central East Antarctic ice cores (Vimeux et al. 1999; Stenni et al. 2001).

Different moisture origins at coastal versus inland locations should influence the distribution of deuterium excess, but also $\delta^{18} \mathrm{O}, \delta \mathrm{D}$, and their relationships to local climatic parameters. Changes in isotopetemperature slopes between locations may be related to atmospheric transport paths. In fact, such spatial slopes very likely include the combined effects of distillation, including temperature gradients between source and site temperatures, and equilibrium fractionation effects along different ranges of temperatures. Isotopic models are used in the next section to assess the relative weight and role of these different physical processes on the Antarctic snow isotopic composition.

\section{Model-data comparisons}

In this section, we use a hierarchy of atmospheric models to provide insights on the physical processes involved in the observed modern spatial distribution of stable isotopes in Antarctic snow. We also analyze the capability of AGCMs to simulate this observed distribution. Section 3a describes the different types of models that have been used; the next sections focus on the use of the models to improve the understanding of the relationships between surface and condensation temperature, surface temperature and isotopic composition, and, finally, the deuterium excess spatial variations.

\section{a. Description of the models and simulations}

Based on an open-system Rayleigh-type distillation scheme (Dansgaard 1964), simple cloud isotopic models are designed to represent the microphysical processes involved in the isotopic fractionation occurring on an isolated air parcel along its cooling trajectory. They may include the modeling of mixed phase processes such as in the mixed cloud isotopic model (MCIM; Ciais and Jouzel 1994), which is used in this paper. Such a model requires assumptions on evaporation conditions (source temperature, relative humidity, wind speed, and initial isotopic composition) and the history of the air mass in terms of temperature and pressure (with a hypothesis on the relationship between condensation and surface temperature). It was shown that the use of the closure assumption for estimating the initial vapor isotopic composition leads to systematic differences compared to simulations conducted with three-dimensional isotopic AGCMs. To address this issue, it was proposed to use isotopic AGCMs water vapor atmospheric composition fields (which ac- count for the mixing of water vapor) to initialize MCIM simulations (Jouzel and Koster 1996; Delmotte et al. 2000).

These models do not account for convection, although they can be used to simulate closed-cloud processes. This potential limitation is minimal for central Antarctica. Several of the microphysical parameters need to be tuned against observations, such as the dependence on temperature of the supersaturation over ice. Despite their intrinsic limitations, such simple distillation models can be used to perform sensitivity studies for different fractionation processes and assess the relative importance of different mechanisms on snow isotopic composition (Masson-Delmotte et al. 2003). The MCIM was used to assess the relative impact of relative humidity and source temperature on Antarctic deuterium excess distribution (Petit et al. 1991), and to infer the origin of Antarctic moisture (Ciais et al. 1995; Delmotte et al. 2000).

To connect microphysical processes with the transport of moisture in the atmosphere and advective versus diffusive moisture transport, a two-dimensional model (latitude versus elevation) was developed (Fisher 1990). A similar intermediate complexity model (Hendricks et al. 2000) was improved and ran on two transport paths to Antarctica, to show the importance of diffusive moisture transport at high latitudes (Kavanaugh and Cuffey 2003). The model was used to perform sensitivity tests by changing climatic parameters, including source effects and hydrological cycle changes, and assess the magnitude of these effects on Antarctic snow isotopic composition. It showed spatial changes in the isotope-temperature slope increasing inland and a rather homogeneous influence of relative humidity on deuterium excess, in contrast to earlier studies (Petit et al. 1991). As for MCIM-type models, the condensation temperature is modeled as a function of the surface temperature, and several parameters need to be adjusted against the observations.

With the goal of reconciling the calculation of isotopic fractionation and realistic transport paths, a methodology was developed to simulate the isotopic composition of individual snowfall events (Helsen et al. 2006), using back trajectories derived from atmospheric reanalyses (Reijmer et al. 2002) and isotopic calculations performed with MCIM, initialized from fields of water vapor isotopic composition from the ECHAM4 isotopic AGCM (Werner and Heimann 2002). Along trajectories, increases in specific humidity were taken into account by recharging the air mass with local moisture associated with the isotopic composition derived from ECHAM4 climatological fields. This approach was extended for the full Antarctic continent 


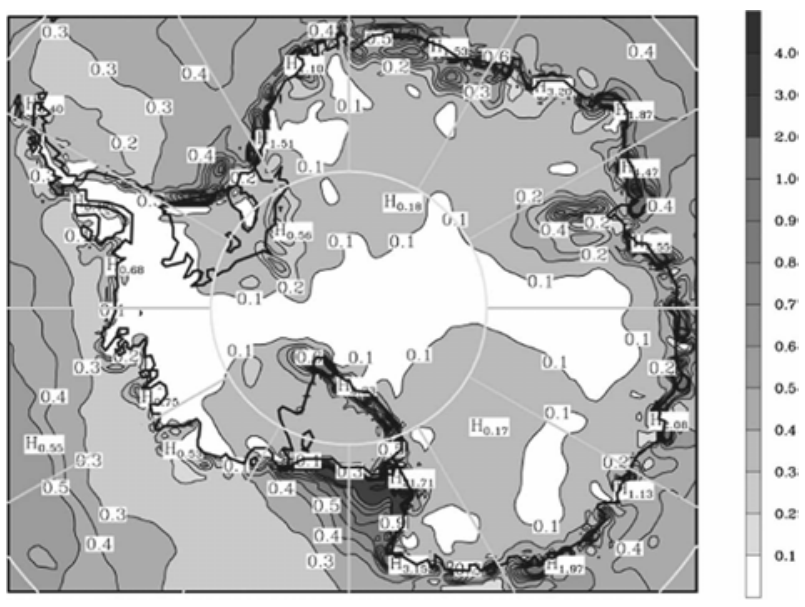

FIG. 7. Diagnostic of the fraction of simulated fifth-generation Pennsylvania State University (PSU)-National Center for Atmospheric Research (NCAR) Mesoscale Model (MM5) annual precipitation that is removed from the surface by sublimation (Bromwich et al. 2004).

over a 22-yr period (Helsen et al. 2007). The 40-yr European Centre for Medium-Range Weather Forecasts (ECMWF) Re-Analysis (ERA-40) was used to determine the condensation temperature, which is not derived from surface temperature, as is commonly done with distillation models (see next section).

Regional atmospheric circulation models have been specifically developed for Antarctica, including parameterizations for processes within the boundary layer, such as snow drift. These models are used to assess the Antarctic surface mass balance (Gallee et al. 2001; Bromwich et al. 2004; Van de Berg et al. 2006), and therefore have a strong focus on moisture transport.

Here we use these models to analyze the transport of moisture toward Antarctica and the relationship between condensation and surface temperature. Although the inclusion of stable isotopes of water in regional atmospheric models has recently been developed for other regions (Sturm et al. 2005), this approach has not yet been applied to Antarctica, limiting the direct comparison with the observed spatial distribution of stable isotopes. Regional atmospheric models provide information that is crucial for the quantification of some postdepositional effects, such as surface snow drift and sublimation.

Figure 7 shows the result of a model study in Antarctica, which points to much larger sublimation effects $(40 \%)$ in coastal areas than in central locations (Bromwich et al. 2004). At sites with weak surface winds, such as Vostok (Ekaykin et al. 2004) and Dome C (Frezzotti et al. 2004; Urbini et al. 2008), mass balance surveys have shown that sublimation is about $10 \%$ of precipitation. The area characterized by such weak surface winds represents only $\sim 10 \%$ of the Antarctic surface. At all of the other survey sites (Frezzotti et al. 2004; Frezzotti et al. 2007), wind-driven sublimation accounts for $20 \%-75 \%$ of the annual precipitation. Sublimation itself is not expected to modify the isotopic composition of the remaining surface snow. However, it can induce a seasonal bias if there is a preferential seasonal removal of surface snow. Sublimation can further provide a local moisture source that may not be negligible, and could impact the firn isotopic composition when associated with depth hoar formation (inverse sublimation) or water vapor diffusion with potential impacts both on mean isotopic values and their variability. Only a few studies have been dedicated to these aspects (Satake and Kawada 1997; Neumann and Waddington 2004).

Several isotopic AGCMs have been developed since the pioneering work of Joussaume et al. (1984) and Jouzel et al. (1987b). Sensitivity studies have been conducted with respect to model parameterizations (Jouzel et al. 1991; Schmidt et al. 2005). These showed, for instance, the importance of supersaturation parameterization to the representation of Antarctic snow deuterium excess distribution. The model-data comparisons in the Antarctic were often limited by the resolution of the models (Werner et al. 2001) and their representation of the present-day climate, including the surface temperature range (Hoffmann et al. 2000). The sources of artifacts in the isotope-temperature relationships in Antarctica (such as changes in moisture origin, transport, seasonality/intermittency of snowfall, and inversion strength) have been explored on the interannual scale (Werner and Heimann 2002; Noone and Simmonds 2002b).

The isotopic AGCMs offer the advantage of consistent simulations of climate and isotopic processes, but make it difficult to isolate the impact of each process on the isotopic composition of precipitation (Table 1). Standardized simulations are archived on the the Stable Water Isotope Intercomparison Group (SWING) Web site (available online at http://atoc.colorado.edu/ $\mathrm{dcn} /$ SWING/index.php). Here we use the mean results from SWING S1B 1870-2003 simulations conducted with three AGCMs [ECHAM4, the Melbourne University GCM (MUGCM), and the Goddard Institute for Space Studies Model E (GISS-E)].

\section{b. Relationship between surface temperature and condensation temperature}

ERA-40 was used to examine the relationship between annual mean surface air temperature and annual mean (weighted with accumulation amount and occur- 
rence) condensation temperature, estimated by the temperature at the vertical level of the maximum condensed moisture (Helsen et al. 2007). The result shows a linear relationship between condensation and surface temperature (Fig. 8a). The slope of this relationship is 0.65 , in fair agreement with the 0.67 slope suggested by either Jouzel and Merlivat (1984) or recent syntheses of Antarctic observations (Connolley 1996) between inversion and surface temperature; however, there is a systematic offset, with condensation temperature being higher than the inversion temperature. Both ERA-40 and the observations show that the inversion temperature-surface temperature method used for MCIM is not suitable for coastal areas, which is as also observed by Ekaykin (2003). Moreover, seasonal vertical temperature profile observations point to very large variations of inversion strength (Connolley 1996).

Another approach to analyzing the relationship between surface and condensation temperature is to use mesoscale atmospheric models specifically designed to capture Antarctic atmospheric processes, such as ice cloud microphysics and boundary layer dynamics that are not fully resolved in AGCMs. A 40-km-resolution simulation of the Modèle Atmosphérique Régional (MAR) mesoscale Antarctic model (Gallée and Schayes 1994) has been forced by ERA-40. In this simulation, the instantaneous condensation temperature has been weighted by the latent heat release both temporally and vertically (vertical integral of air temperature multiplied by latent heat release, divided by the vertical integral of latent heat release). This weighting approach may be partly biased because it does not take into account the sublimation that is parameterized when precipitation crosses undersaturated air layers. The modeled relationship between weighted condensation temperature and annual mean surface temperature (Fig. 8b) reveals that (i) it falls below the classical spatial relationship with a slope of 0.67 , and (ii) the simulated condensation temperature is colder than the surface temperature on the central Antarctic plateau. Preliminary analyses suggest that this model result is related to the formation of high-elevation $(20 \mathrm{~km})$ clouds simulated by MAR during the austral winter, and to "warm surface events." A very high-elevation advection of moisture during winter is coherent with the seasonal cycle of natural tritium deposition observed at the South Pole (Jouzel et al. 1982; Fourré et al. 2006).

Our surface database does not allow us to explore the relationships between isotopic composition and temperatures above the surface, or the seasonal aspects. Similarly, condensation temperature is not a standard output of AGCMs, which limits our ability to explore
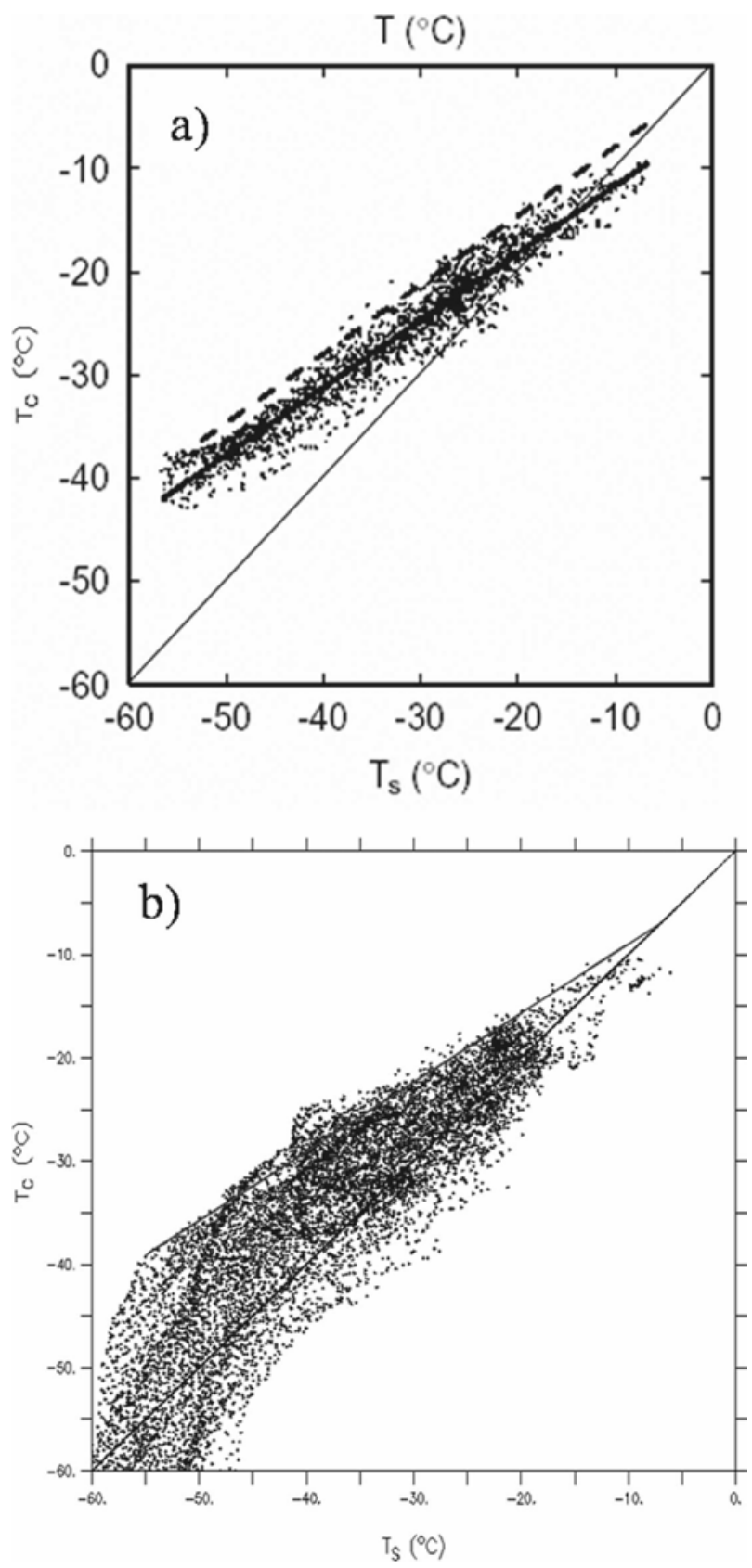

FIG. 8. Condensation vs surface temperature is shown. (a) ERA-40 (1980-2002) relationship between annual surface temperature $\left({ }^{\circ} \mathrm{C}\right)$ and weighted annual mean condensation temperature $\left({ }^{\circ} \mathrm{C}\right)$, diagnosed at the elevation of maximum moisture condensation and weighted by the snowfall amounts, is shown. The solid thick line is the best fit, and the dashed line is the relationship between surface and inversion temperature derived from observations by Jouzel and Merlivat (1984). The thin black line is the 1:1 relationship. (b) A similar diagnosis is calculated using the MAR 40-km-resolution mesoscale model forced by ERA-40 (1980-99). The condensation temperature $\left(T_{c}\right.$; vertical axis) is calculated using a weighting by the latent heat release (vertically and temporally). The blue line is the relationship derived from the spatial observations of Jouzel and Merlivat (1984) (slope of 0.67) and the black line is the $1: 1$ relationship. 
these critical aspects from the SWING database. Simple isotopic models, such as MCIM can, however, be used to test the consequences of different inversion strengths on the final Antarctic isotopic composition.

\section{c. Relationships between surface temperature, stable isotope composition, and simulated water cycle}

\section{1) Simple MOdel APPROACH}

With the tuning strategy developed in MassonDelmotte et al. (2004), the MCIM parameterizations were adjusted to obtain the best fit with the Dumont d'Urville-to-Dome C traverse. Key model microphysical parameterizations are related to the supersaturation on ice crystals (see the discussion on deuterium excess) and the proportion of condensate that is removed from the cloud (closed- versus open-cloud distillation).

Figure 9 displays the results that are obtained when this model version is run on an idealized path calculated with moisture source temperatures of $12^{\circ}$ and $17^{\circ} \mathrm{C}$, and a final site condensation temperature of $-43^{\circ} \mathrm{C}$. The isotopic depletion results mainly from the prescribed cooling path and the effect of equilibrium fractionation. Figure 9 also shows the different slopes obtained versus condensation temperature and versus "surface temperature" (taking into account the relationship between inversion and surface temperature).

The tuning strategy yields a simulated $\delta \mathrm{D}$-surface temperature slope of $6.5 \%\left({ }^{\circ} \mathrm{C}\right)^{-1}$ for surface temperatures below $-10^{\circ} \mathrm{C}$ and $6.7 \%$ o $\left({ }^{\circ} \mathrm{C}\right)^{-1}$ for surface temperatures below $-30^{\circ} \mathrm{C}$. The observed increase in isotope-temperature slopes at low temperatures is therefore captured by simple distillation models with a constant moisture source. Although the isotopetemperature slope is coherent with observations, the MCIM does not simulate the level of isotopic depletion observed in the central plateau; this bias can reach 50\%o at $-50^{\circ} \mathrm{C}$. Salamatin et al. (2004) have suggested that this bias may be due to an underestimation of kinetic effects. Finally, Fig. 9 shows the limited imprint of changes in evaporation conditions (considering only one moisture source, and explored only in terms of moisture source temperature) on $\delta \mathrm{D}$ in a simple model approach.

\section{2) Isotopic AGCMs}

Isotopic AGCMs fully combine the effects of moisture origin and phase changes on the precipitation isotopic composition. Figure 10 a shows the $\delta \mathrm{D}$-surface temperature simulated by three isotopic AGCMs on a subset of grid points corresponding to the observational database. We have used the 2-m surface air tempera-
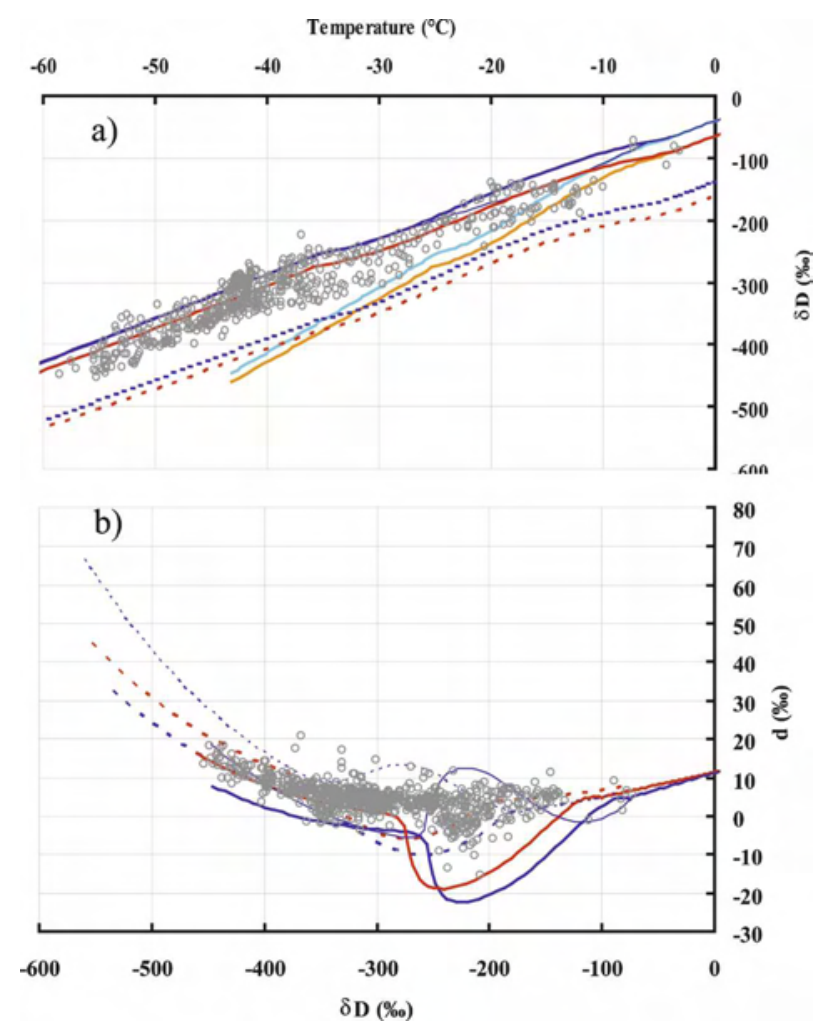

FIG. 9. MCIM simulations are compared with surface data. (a) The relationship between surface temperature $\left({ }^{\circ} \mathrm{C}\right)$ and $\delta \mathrm{D}(\%)$ is shown. The observations from Fig. 5 are displayed as gray circles. A first MCIM simulation is conducted with a supersaturation/ temperature slope of -0.0038 and a moisture source temperature of $285 \mathrm{~K}$. The isotopic composition of precipitation is displayed against condensation temperature (light blue) and estimated surface temperature using a slope of 0.67 (dark blue). The isotopic composition of vapor is displayed in dashed dark blue against surface temperature. A sensitivity test is conducted by changing the supersaturation dependency on temperature to a slope of -0.002 (thin blue line, almost undistinguishable from the dark blue line). A second MCIM simulation is performed with a moisture source temperature of $290 \mathrm{~K}$ (thick red line: precipitation isotopic composition as a function of surface temperature; thick orange line: precipitation isotopic composition as a function of condensation temperature; and dashed red line: vapor isotopic composition as a function of surface temperature). (b) Same as (a), but showing the relationship between surface $\delta \mathrm{D}(\%)$ and deuterium excess (\%o). Thick blue lines: moisture source of $285 \mathrm{~K}$; thin blue line: same moisture source but change in supersaturation/temperature slope; dashed lines: vapor isotopic composition; and red lines: moisture source of $290 \mathrm{~K}$. The spurious variations result from threshold effects linked with the mixed phase transitions.

ture that is available in the SWING database. The model-data comparison is affected by model climatological biases, such as a warm bias for inland Antarctica, which is particularly evident in MUGCM.

When considering all of the relevant grid points, the simulated $\delta \mathrm{D}$-surface temperature slopes range from 
(a)

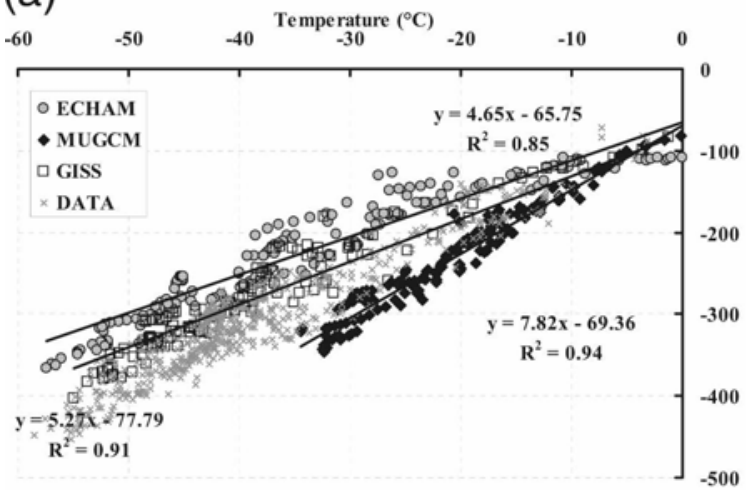

(c)

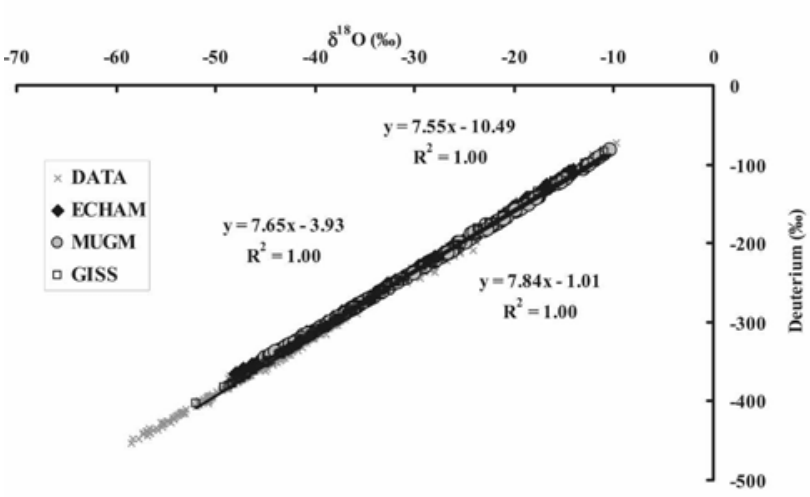

(b)

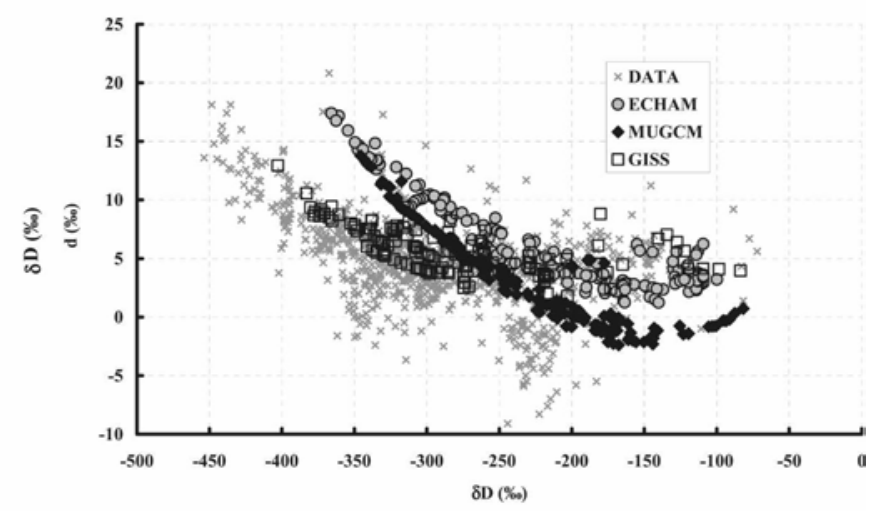

(d)

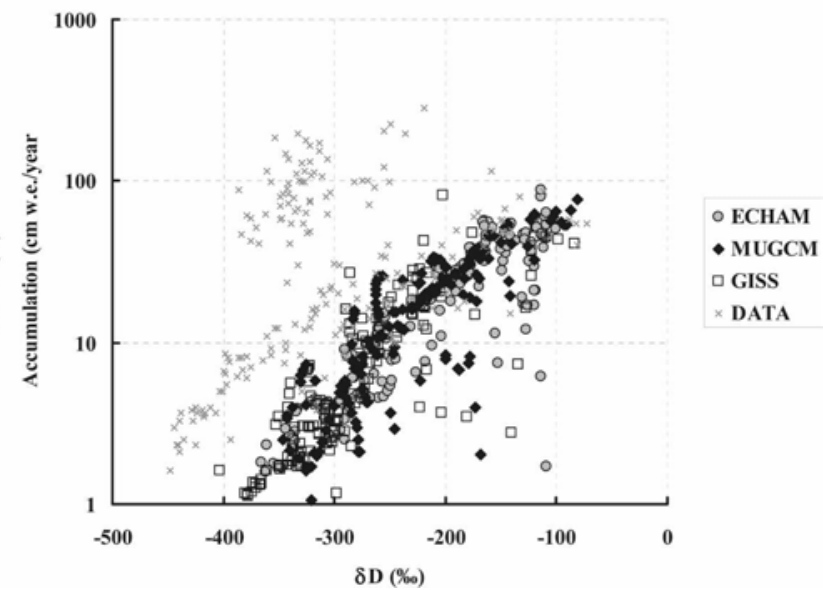

FIG. 10. Comparison between three isotopic atmospheric general circulation models (ECHAM4, MUGCM, GISS-E) and surface data is shown (as in Fig. 5). Relationships between (a) annual mean surface temperature $\left({ }^{\circ} \mathrm{C}\right)$ and precipitation-weighted annual mean $\delta \mathrm{D}(\%)$, (b) precipitation-weighted annual mean surface $\delta \mathrm{D}(\%)$ and deuterium excess (\%o), (c) precipitation-weighted annual mean $\delta^{18} \mathrm{O}(\%)$ and $\delta \mathrm{D}(\%)$, and (d) annual mean accumulation (extracted from the simulated precipitation minus evaporation) and precipitation-weighted annual mean $\delta \mathrm{D}(\%)$ are shown.

$4.6 \%$ o $\left({ }^{\circ} \mathrm{C}\right)^{-1}$ to $7.8 \%$ o $\left({ }^{\circ} \mathrm{C}\right)^{-1}$, framing the observational relationship of $6.3 \%$ o $\left({ }^{\circ} \mathrm{C}\right)^{-1}$. Below $-30^{\circ} \mathrm{C}$, the GISS-E and ECHAM4 models simulate a larger slope [respectively, $6.5 \%$ and $5.7 \%$ o $\left({ }^{\circ} \mathrm{C}\right)^{-1}$ ], but it is not as large as that observed $\left[6.9 \%{ }^{\circ}\left({ }^{\circ}\right)^{-1}\right]$. Although not shown here, similar results are obtained for $\delta^{18} \mathrm{O}$. Isotopic AGCMs fail to reproduce the observed inland depleted values, in part because of the warm bias found in the models.

Because surface temperature cannot fully account for the lack of depletion in some of the models, other mechanisms have been explored. Helsen et al. (2007) have combined back trajectories with MCIM simulations using ECHAM4 three-dimensional vapor isotopic composition climatological fields. They have constructed an alternative climatology of Antarctic snowfall isotopic composition and produced high-resolution estimates of spatial isotope-temperature slopes. Their results suggest regional slope maxima in areas such as Victoria Land/Wilkes Land (consistent with the observations), and a minimum slope on the central plateau, which is not coherent with our database. They attribute this mismatch to a simulation of the local moisture contribution on the inland plateau and rule out seasonality effects on isotopic biases.

\section{3) Role of ALtitudinal Moisture ADVECTiON}

Figure 10d displays the observed and modeled distribution of accumulation versus $\delta \mathrm{D}$. Although each isotopic AGCM has a specific accumulation versus temperature distribution and a specific isotope versus temperature distribution, it is striking that they exhibit the same relationship between simulated annual mean accumulation (estimated by precipitation minus evapora- 
tion) and isotopic depletion. The model-data comparison therefore points to the following two systematic model biases: (i) a lack of isotopic depletion, even in AGCMs simulating a correct range of Antarctic surface temperature, and (ii) an underestimation of moisture supply to inland Antarctica (specifically at temperatures below $-30^{\circ} \mathrm{C}$ ). Other studies have already suggested that ERA-40, ECHAM4, and other AGCMs produce less accumulation than that observed in inland Antarctica (Van de Berg et al. 2006; Krinner et al. 2007).

All isotopic model types tested here underestimate the degree of depletion over inland Antarctica. Although simple models may capture the observed isotopetemperature slope after appropriate tuning without requiring different moisture sources, AGCMs point to different moisture origins for coastal versus inland moisture. The lack of depletion in the AGCMs may therefore be linked to their representation of the transport of moisture toward central Antarctica.

Moisture origin effects may be involved in the model biases. Different moisture advection paths are expected in coastal versus inland Antarctica, as evidenced by the analysis of moisture advection (Fig. 11; section 3d) and back trajectories. Figure 12a displays the latitude/ altitude distribution of ECHAM4 annual mean water vapor isotopic composition, together with two trajectories illustrating the different transportation height of water vapor toward a coastal and a continental Antarctic site. The coastal site receives moisture that has traveled from Southern Ocean high latitudes, and is transported toward the coastal locations of the continent where it precipitates. In contrast, the moisture that precipitates in central Antarctica has been traveling at higher altitudes, which reduces the high-latitude ocean moisture contribution (Noone and Simmonds 2002b; Noone 2008). Atmospheric water vapor isotopic composition along such trajectories clearly shows that differences in isotopic composition across Antarctica are not caused only by temperature gradients along moisture transport, but also are due to differences in transportation height.

Several physical reasons may be involved in these model-data mismatches, for example, (i) state-of-theart AGCMs do not resolve very shallow inversion layers because of their representation of boundary layer processes, (ii) they usually have no specific simulation of diamond dust formation and effects, (iii) the simulated atmospheric dynamics may be affected by gridpoint singularities at South Pole, and (iv) their representation of polar cloud distribution and microphysics may be problematic (see next section).

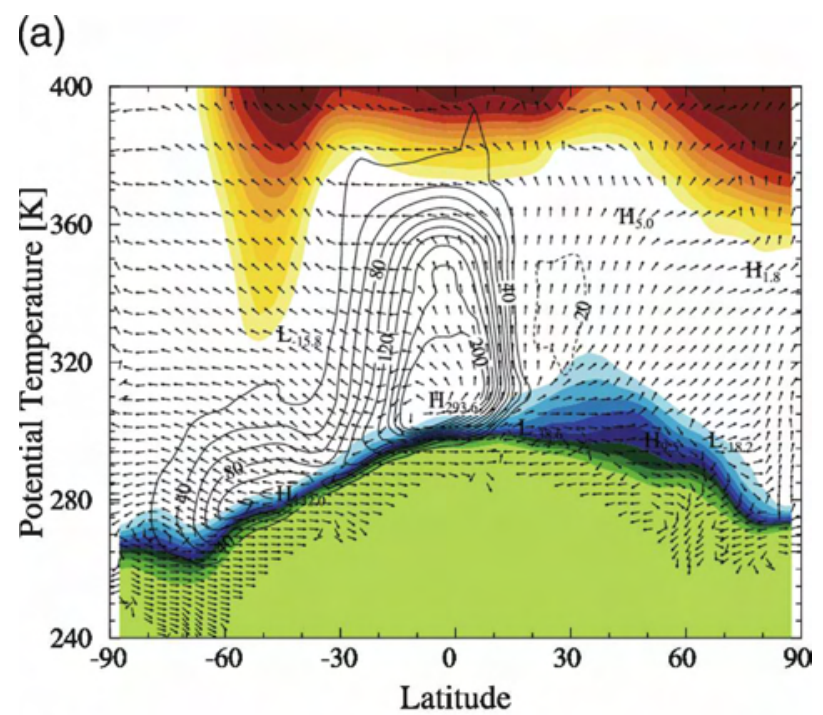

(b)

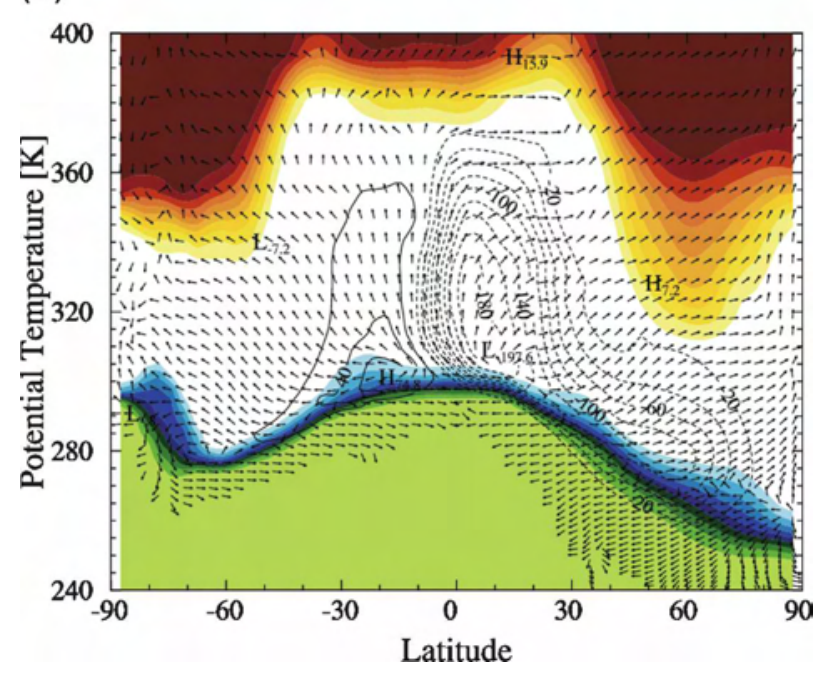

FIG. 11. Vertical profiles are shown. (a) Isentropic mass transport streamfunction (black isolines of $10 \times 10^{19} \mathrm{~kg} \mathrm{~s}^{-1}$; negative values are dashed) and water vapor flux (vectors) simulated by the MUGCM and represented as a function of latitude and potential temperature. In these coordinates, arrows directed upward indicate condensation (approximately). Blue-green color contours toward the bottom of the panel represent the frequency of the surface potential temperature of the surface, and orange shading is the frequency of the tropopause potential temperature (frequency contours every $10 \%$ ). Climatological results are for a perpetual July simulation. (b) Same as (a), but for January.

\section{4) Mesoscale modeling}

Mesoscale atmospheric models specifically designed for Antarctic climate may help to identify key local processes. Sensitivity studies conducted with the Regional Atmospheric Climate Model (RACMO; Van de Berg et al. 2006; Fig. 13) suggest that reducing the fall speed of ice crystals could induce thicker clouds on the 
(a)

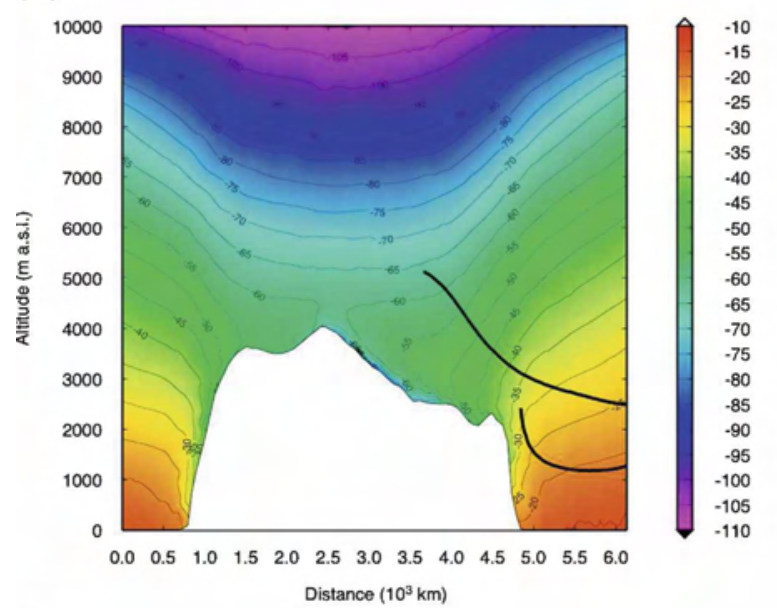

(b)

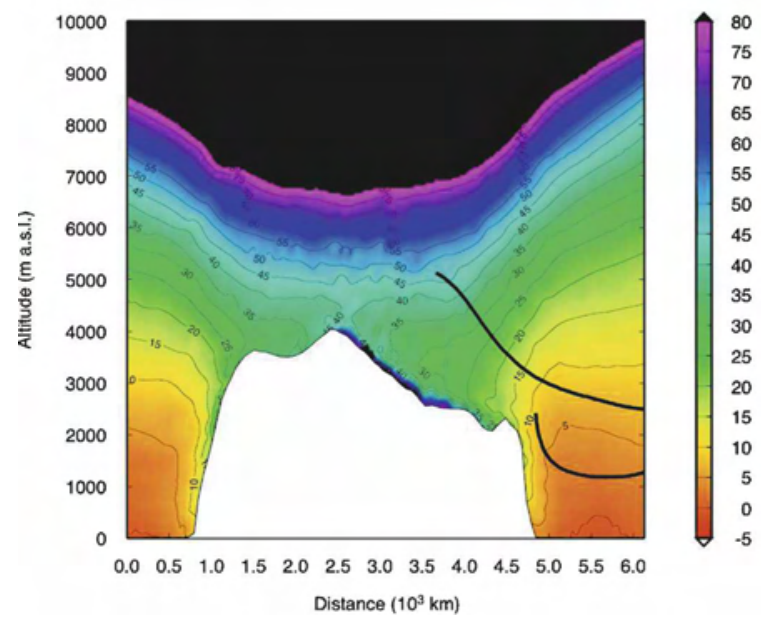

FIG. 12. (a) Vertical transect over Antarctica showing the mean annual $\delta^{18} \mathrm{O}$ values of water vapor in ECHAM4 simulations. Black lines represent trajectories for moisture advection to inland vs coastal areas projected on the transect plane. (b) Same as (a), but for deuterium excess.

Antarctic Plateau, increasing the mean height of condensation and giving a better distribution of accumulation over the continent, more snowfall on the plateau and the escarpment region, and less snowfall on the coastal zone (Van de Berg 2008).

Another mesoscale atmospheric model (MAR) has been used to diagnose the condensation temperature. Figure $8 \mathrm{~b}$ clearly suggests that the latent heat-weighted condensation temperature can be significantly colder than the annual surface mean temperature in the coldest Antarctic central areas. Preliminary analyses of these simulations suggest that these cold condensation temperatures are due to the occurrence of highelevation cloudiness (up to $20 \mathrm{~km}$ ) associated with winter warm surface events. These results could be com- patible with measurements of winter maximum tritium deposition at the South Pole (Jouzel et al. 1982; Fourré et al. 2006).

Considering the modeled vertical distribution of isotopic composition (Figs. 12a,b), precipitation formed at higher altitudes would be more isotopically depleted. This sensitivity study suggests that the biases observed for atmospheric models may be linked to the representation of polar cloudiness at high elevation, and its occurrence and microphysics. The systematic comparison of model results with Antarctic surface snow isotopic composition and surface mass balance databases may improve the representation of the water cycle above Antarctica. This has potential consequences for future mass balance simulation (Krinner et al. 2007).

\section{d. Modeling the deuterium excess spatial distribution}

In this section, we discuss first the modeled $\delta \mathrm{D}-\delta^{18} \mathrm{O}$ relationship and second the simulated deuterium excess; these two aspects are complementary approaches on the differential fractionation between isotopic forms of water vapor.

The MCIM simple isotopic model used here shows a $\delta \mathrm{D}-\delta^{18} \mathrm{O}$ slope of $7.8 \%$ o $(\%)^{-1}$ for surface temperatures below $-10^{\circ} \mathrm{C}$ and a slope of $7.3 \%$ o $(\%)^{-1}$ for temperatures below $-30^{\circ} \mathrm{C}$. The simulated range of slopes is consistent with observations and mainly results from the dependency of equilibrium fractionation coefficients on temperature.

AGCM simulations (Fig. 10b) display "model dependent" meteoric water lines, with slopes calculated at the Antarctic scale of $7.55 \%$ (\%о) $)^{-1}$ (MUGCM), 7.65\% $(\%)^{-1}$ (ECHAM4), and 7.84\% (\%o $)^{-1}$ (GISS). They exhibit a $\sim 0.2$ decrease of the observed slope at lower temperatures, which seems weaker than the $\sim 0.5$ decrease shown by the observations. It must be noted that most of the surface snow isotopic data may be affected by postdepositional effects that are not taken into account in the precipitation isotopic composition modeling. There is no large difference between precipitation and accumulated snow in AGCMs. Further detailed study of the isotopic composition of Antarctic snowfall and its evolution in the upper firn layers may help to advance in the understanding of these differences.

The intercept of the meteoric water line of the observations is $-5 \%$, compared with $-6 \%$ in the MCIM simulations, and a large range is found in the AGCM results (from $-1 \%$ o to $-10 \%$ ). These different intercepts may result from both kinetic effects (i.e., related to the parameterization of the supersaturation) and different equilibrium effects (different temperature ranges and different distillation intensities). This dispersion is 
(a)

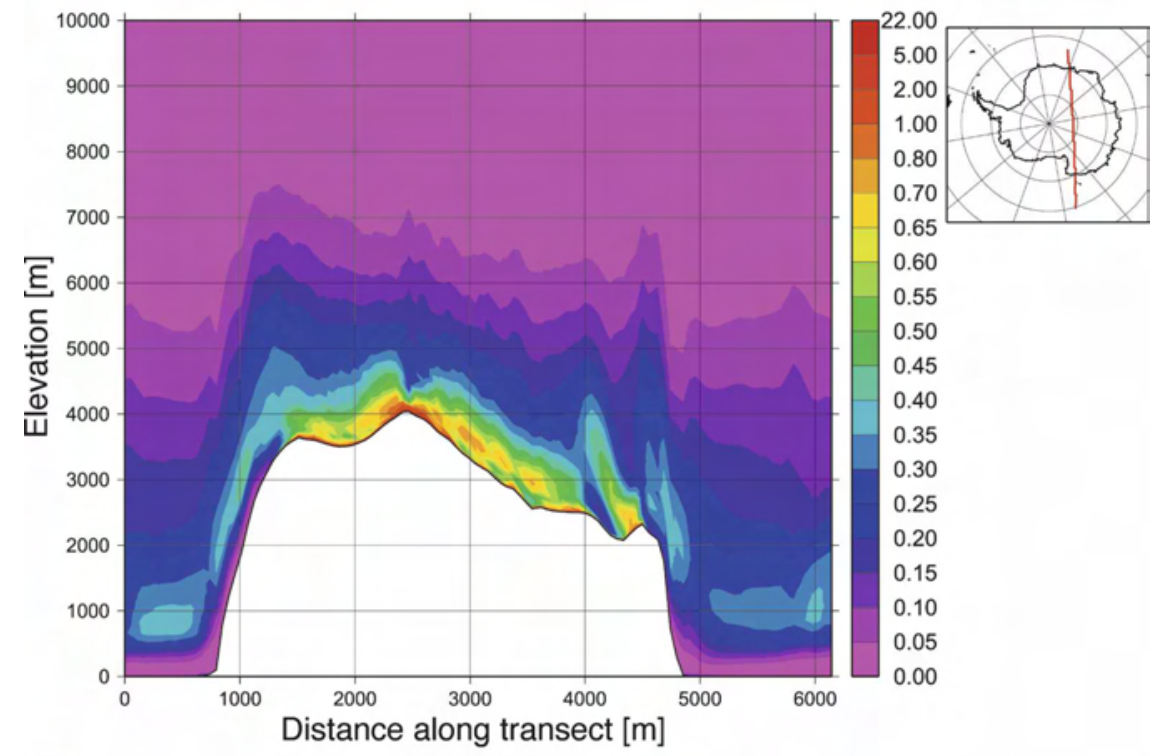

(b)

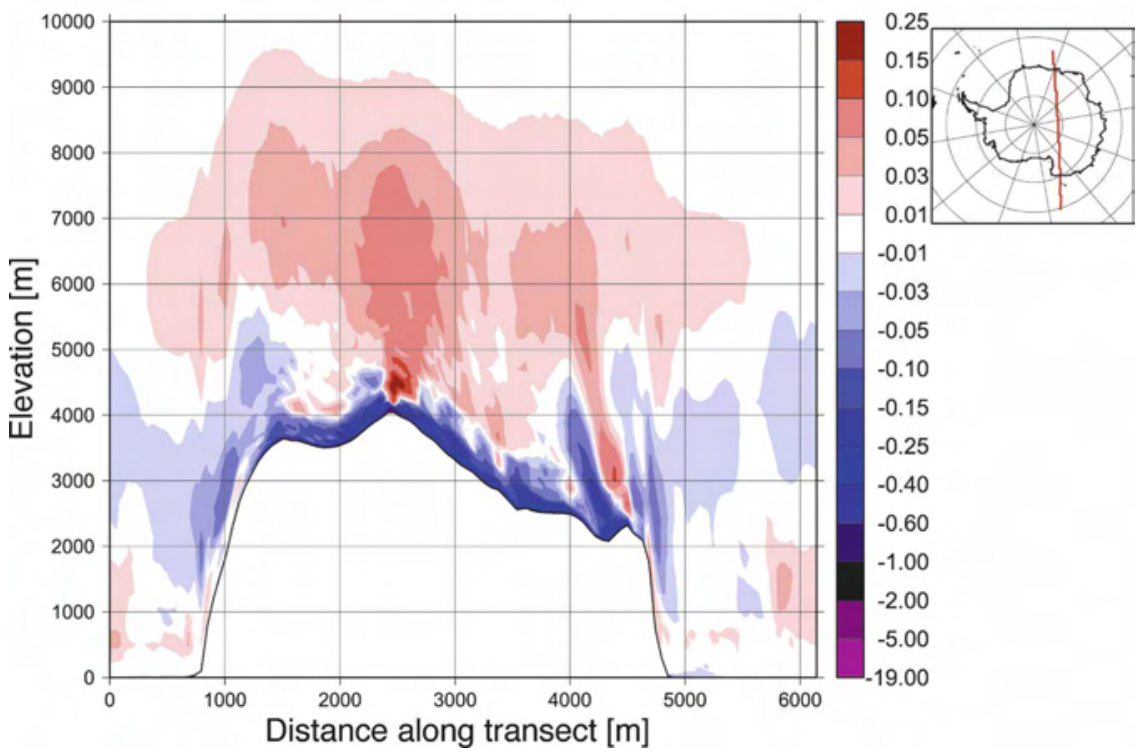

FIG. 13. (a) Vertical distribution of snow formation as simulated by RACMO (standard model version) is shown. The model results are shown as the fraction of contribution to the total snowfall per kilometer height, along a transect across the East Antarctic plateau and Dome A. Elevation and length along the transect are displayed (m). (b) Same as (a), but for the change in vertical distribution of snow formation in a sensitivity experiment with respect to the standard parameterization (for a reduced ice crystal fall speed).

also obvious when considering the simulated deuterium excess as a function of $\delta \mathrm{D}$ (Fig. 10c). None of the simulations produces negative deuterium excess values that have been measured in the Dry Valleys; however, the models used here do not resolve such geographical features. It cannot be ruled out that postdepositional processes are associated with such negative values. Earlier modeling studies had also suggested that water evaporated from sea ice-covered oceans could provide very low deuterium excess snowfall at coastal locations (Noone and Simmonds 2004).

The shape of the deuterium excess versus $\delta \mathrm{D}$ relationship is strongly affected by biases in isotopic depletion, as described above. Obtaining a reasonable simu- 
lation of deuterium excess values is linked to the representation of supersaturation and its dependence on temperature as discussed by Schmidt et al. (2005). In GISS-E, which shows the best agreement with the observations in terms of meteoric water line, the model does not capture the combination of highly depleted $\delta \mathrm{D}$ and high deuterium excess values that is present in the observations. Again, this model-data mismatch could be reconciled with an underestimation of the highelevation moisture supply to inland Antarctica. In the previous section, we have suggested that cloud parameterizations may have a significant role on this aspect of moisture advection.

Deuterium excess data differ at elevations below and above $2000 \mathrm{~m}$, possibly associated with different moisture advection paths. Given the resolution limitations for capturing topographic effects and the current lack of realism of deuterium excess in current AGCMs, it is difficult to go further in model-data comparisons. Dynamical considerations, however, support our suggestion. Noone and Simmonds (2002a) have used the Froude number to show a division between coastal flow that cannot penetrate inland Antarctica and freetropospheric flow that can.

Figures 11a,b show the zonal mean isentropic meridional mass streamfunction that is simulated by the Melbourne, Australia, AGCM for July and January, respectively. The isentropic coordinate can be used to track the diabatic component of circulation as the crossisentropic flow (Noone 2008), and therefore the Lagrangian aspect of the flow (similar to the back trajectories). Different flow paths are clearly visible for coastal versus inland Antarctic locations, and for different seasons. In winter (Fig. 11a), the advection of moisture toward inland Antarctica is mostly provided by midtroposphere airflow from the subtropics, partially replenished by intense vertical mixing associated with midlatitude cyclonic activity. In summer (Fig. 11b), the atmospheric circulation is less intense and less efficient at transporting moisture; associated with a minimum surface potential temperature at $65^{\circ} \mathrm{S}$, the summer situation results in a stronger isolation of coastal flow (vertical arrows perpendicular to the surface potential temperature in summer indicate that moisture is trapped in the coastal Antarctic areas). This diagnostic supports the argument that two distinct moisture advection transport paths are expected-one for coastal and one for inland Antarctic locations. The increase in deuterium excess in central Antarctica may therefore reflect not only different moisture sources, but also different atmospheric condensation histories.

The strong vertical deuterium excess gradients simu- lated here by the ECHAM4 AGCM (Fig. 12b) would support this interpretation that different moisture advection paths account for different deuterium excess values at coastal versus inland locations. Isotopic AGCM results show that Antarctic deuterium excess (Schmidt et al. 2007) and $\delta^{18} \mathrm{O}$ (Noone and Simmonds 2002a) can be strongly influenced by changes in the annular mode. Over a 22-yr time period, back trajectory calculations initialized by ECHAM4 water vapor climatology (Helsen et al. 2007) suggests a progressive evolution of deuterium excess over transport without dramatic change during the final stage of transport. To assess the influence of moisture source (evaporation) versus airmass trajectory effects, further analyses should combine moisture origin tagging with isotopic modeling, along the lines of Delaygue et al. (2000). Because of a general lack of isotopic measurements on atmospheric vapor, the interplay between equilibrium and kinetic fractionation is currently not known. Therefore, a full understanding and realistic modeling of processes governing the spatial distribution of deuterium excess in Antarctic still remains a challenge.

\section{Conclusions and perspectives}

Our compilation of surface Antarctic snow composition provides better spatial coverage than earlier studies, although it is still strongly biased toward East Antarctic locations. There is a clear need to extend the spatial distribution of surface snow isotopic composition in many places of Antarctica. This is a focus of the traverses to be conducted as part of the 2007-09 International Polar Year. Systematic measurements of water vapor and snow isotopic composition should allow us to disentangle the effect of depositional and postdepositional processes. Intensive efforts based on accumulation histories derived from ice cores suggest that, despite a warming detected in winter tropospheric temperature in Antarctica during the past decades (Turner et al. 2006), there is no significant change in Antarctic accumulation since the International Geophysical Year in 1957-58 (Monaghan et al. 2006). Syntheses of trends in stable isotope fluctuations may provide a means for detecting changes in the atmospheric moisture supply to Antarctica, including subtle changes in moisture origin.

This database confirms earlier findings regarding the spatial variability of the isotope distribution in relation to geographical parameters (latitude, distance from the coast, and elevation). Regression models provide methods to generate Antarctic-wide fields of surface snow isotopic composition, which may be useful for the forcing of ice sheet models. The dependency of stable iso- 
topic composition on temperature can now be analyzed separately for coastal and inland regions. It shows regional signatures, with variations mostly within $20 \%-$ $30 \%$ of the continental average isotope-temperature slope.

Significant changes in the deuterium excess values below and above 2000-m elevation are observed, suggesting that dynamical processes in the atmospheric moisture advection may induce differences in moisture origin and atmospheric transport path. This result suggests that isotopic analyses from new ice cores drilled at high-accumulation, coastal areas would provide regional climate records with integrated information on local temperature trends and regional hydrological cycle changes. Obtaining such well-dated, high-resolution records of the last millennia is one of the challenges of the International Partnership for Ice Core Science (see information online at http://www.pages. unibe.ch/science/initiatives/ipics/index.html).

The model-data comparison points to a systematic mismatch between the AGCMs' accumulation and isotopic depletion simulations over inland Antarctica. We suggest that this disagreement is related to the representation of cloud microphysics and inadequate representation of large-scale advection of water vapor. Dynamical considerations support the interpretation of deuterium excess data as tracers of different moisture transport paths at different atmospheric heights. To progress in the understanding of the isotopic processes leading to the observed deuterium excess spatial distribution, further observational studies are needed regarding additional tracers of the water cycle, such as $\delta^{17} \mathrm{O}$ of snow (Landais et al. 2008), postdepositional effects, and the monitoring of water vapor isotopic composition near and above Antarctica. Finally, the model-data comparison calls for new Antarctic observational studies to reexamine cloud microphysical processes, kinetic fractionation, and deuterium excess distribution in the atmosphere.

Acknowledgments. Stable isotope analyses at LSCE have been funded by CEA, CNRS, ACI C3. Italian research was funded by National Antarctic Research Program (PNRA). The calibration of the isotopetemperature relationship is part of the European Commission 6th PCRDT EPICA-MIS and French ANR PICC projects. We thank Gabrielle Dreyfus, Yao Tandong, and Ellen Mosley-Thompson for providing information and comments, as well as four dedicated reviewers. This work is a contribution to the European Project for Ice Coring in Antarctica (EPICA), a joint European Science Foundation/European Commission scientific program, funded by the EU and by national contribu- tions from Belgium, Denmark, France, Germany, Italy, the Netherlands, Norway, Sweden, Switzerland, and the United Kingdom. The main logistic support was provided by IPEV and PNRA (at Dome C) and AWI (at Dronning Maud Land).

\section{REFERENCES}

Aristarain, A. J., 1980: Etude glaciologique de la calotte de l'île de James Ross (péninsule Antarctique). Ph.D. thesis, Université Joseph Fourier, $130 \mathrm{pp}$.

- R. J. Delmas, and M. Stievenard, 2004: Ice core study of the link between sea-salt aerosol, sea-ice cover and climate in the Antarctic Peninsula area. Climatic Change, 67, 63-86.

Becagli, S., and Coauthors, 2004: Chemical and isotopic snow variability in East Antarctica along the 2001/02 ITASE traverse. Ann. Glaciol., 39, 473-482.

Bromwich, D. H., Z. Guo, L. Bai, and Q.-S. Chen, 2004: Modeled Antarctic precipitation. Part I: Spatial and temporal variability. J. Climate, 17, 427-447.

Brook, E. J., and Coauthors, 2005: Timing of millennial-scale climate change at Siple Dome, West Antarctica, during the last glacial period. Quat. Sci. Rev., 24, 1333-1343.

Brown, J., and I. Simmonds, 2004: Sensitivity of the $\delta^{18} \mathrm{O}$ temperature relationship to the distribution of continents. Geophys. Res. Lett., 31, L09208, doi:10.1029/2004GL019870.

Caillon, N., J. P. Severinghaus, J. M. Barnola, J. C. Chappellaz, J. Jouzel, and F. Parrenin, 2001: Estimation of temperature change and of gas age-ice age difference, $108 \mathrm{kyr}$ B.P., at Vostok, Antarctica. J. Geophys. Res., 106, 31 893-31901.

Ciais, P., 1991: Forages profonds et sites cotiers en Antarctique: Données isotopiques et climat des 15000 dernieres années. Spécilalité: Physique-météorologie-océanologie. Ph.D. thesis, Université Paris 6, 390 pp.

— tion: An isotopic model including mixed cloud processes. $J$. Geophys. Res., 99, 16 793-16 803.

,-- J. R. Petit, V. Lipenkov, and J. C. W. White, 1994: Holocene temperature variations inferred from six Antarctic ice cores. Ann. Glaciol., 20, 427-436.

— J. W. C. White, J. Jouzel, and J. R. Petit, 1995: The origin of present-day Antarctic precipitation from surface snow deuterium excess data. J. Geophys. Res., 100, 18 917-18 927.

Connolley, W. M., 1996: The Antarctic temperature inversion. Int. J. Climatol., 16, 1333-1342.

Craig, H., 1961: Isotopic variations in meteoric waters. Science, 133, 1702-1703.

Cuffey, K. M., R. B. Alley, P. M. Grootes, and S. Anandakrishnan, 1992: Towards using borehole temperatures to calibrate an isotopic paleothermometer in central Greenland. Global Planet. Change, 6, 264-268.

Dahe, Q., J. R. Petit, J. Jouzel, and M. Stievenard, 1994: Distribution of stable isotopes in surface snow along the route of the 1990 International Trans-Antarctica Expedition. J. Glaciol., 40, 107-118.

Dansgaard, W., 1953: The abundance of ${ }^{18} \mathrm{O}$ in atmospheric water and water vapour. Tellus, 5, 461-469. 1964: Stable isotopes in precipitation. Tellus, 16, 436-468.

—_, H. B. Clausen, N. Gundestrup, C. U. Hammer, S. J. Johnsen, P. Kristinsdottir, and N. Reeh, 1973: Stable isotope glaciology. Medd. Grønl., 2, 1-53.

Delaygue, G., V. Masson, J. Jouzel, and R. D. Koster, 2000: The 
origin of Antarctic precipitation: A modelling approach. Tellus, 52B, 19-36.

Delmotte, M., 1997: Enregistrements climatiques à Law-Dome: Variabilité pour les périodes récentes et pour la déglaciation. Ph.D. thesis, Université Joseph Fourier, 300 pp.

_ deuterium excess signal at Law Dome, coastal eastern Antarctica: A southern ocean signature. J. Geophys. Res., 105, 7187-7197.

Ekaykin, A. A., 2003: Meteorological regime of central Antarctic and its role in the isotopic composition of snow thickness. Sciences of Earth and Universe, Université Joseph Fourier, $120 \mathrm{pp}$.

—, V. Y. Lipenkov, N. I. Barkov, J. R. Petit, and V. Masson, 2001: Izotopniy sostav poverhnostnogo sloya snezhnoy tolschi v rayone stantsii Vostok, Tsentral'naya Antarctida (Isotope composition of surface snow in the vicinity of Vostok Station, central Antarctica). Mater. Glyatsiologicheskih Issled., 90, 69-79.

$-,-\longrightarrow,-\longrightarrow$, and V. Masson-Delmotte, 2002: Spatial and temporal variability in isotope composition of recent snow in the vicinity of Vostok Station: Implications for icecore record interpretation. Ann. Glaciol., 35, 181-186.

,-- I. Kuzmina, J. R. Petit, V. Masson-Delmotte, and S. J. Johnsen, 2004: The changes in isotope composition and accumulation of snow at Vostok Station, East Antarctica, over the past 200 years. Ann. Glaciol., 39, 569-575.

EPICA Community Members, 2004: Eight glacial cycles from an Antarctic ice core. Nature, 429, 623-628.

- 2006: One-to-one coupling of glacial climate variability in Greenland and Antarctica. Nature, 444, 195-198.

Epstein, S., and T. Mayeda, 1953: Variations of $\mathrm{O}^{18}$ content of waters from natural sources. Geochim. Cosmochim. Acta, 4, 213-224.

—, R. P. Sharp, and I. Goddard, 1963: Oxygen isotope ratios in Antarctic snow, firn and ice. J. Geol., 71, 698-720.

Fisher, D. A., 1990: A zonally averaged stable-isotope model coupled to a regional variable elevation stable isotope model. Ann. Glaciol., 14, 65-72.

Fourré, E., P. Jean-Baptiste, A. Dapoigny, D. Baumier, J. R. Petit, and J. Jouzel, 2006: Past and recent tritium levels in Arctic and Antarctic polar caps. Earth Planet. Sci. Lett., 245, 56-64.

Frezzotti, M., and Coauthors, 2004: New estimations of precipitation and surface sublimation in East Antarctica from snow accumulation measurements. Climate Dyn., 23, 803-813.

— snow accumulation in East Antarctica from traverse data. $J$. Glaciol., 51, 113-124.

_ , S. Urbini, M. Proposito, C. Scharchilli, and S. Gandolfi, 2007: Spatial and temporal variability of surface mass balance near Talos Dome, East Antarctica. J. Geophys. Res., 112, F02032, doi:10.1029/2006JF000638.

Fujita, K., and O. Abe, 2006: Stable isotopes in daily precipitation at Dome Fuji, East Antarctica. Geophys. Res. Lett., 33, L18503, doi:10.1029/2006GL026936.

Gallée, H., and G. Schayes, 1994: Development of a threedimensional meso- $\gamma$ primitive equation model: Katabatic wind simulation in the area of Terra Nova Bay, Antarctica. Mon. Wea. Rev., 122, 671-685.

- G. Guyomarc'h, and E. Brun, 2001: Impact of snow drift on the Antarctic ice sheet surface mass balance: Possible sensi- tivity to snow-surface properties. Bound.-Layer Meteor., 99 , $1-19$.

Gooseff, M. N., W. B. Lyons, D. M. McKnight, B. H. Vaughn, A. G. Fountain, and C. Dowling, 2006: A stable isotopic investigation of a polar desert hydrologic system, McMurdo Dry Valleys, Antarctica. Arct. Antarct. Alp. Res., 38, 60-71.

Goosse, H., and Coauthors, 2004: A late medieval warm period in the Southern Ocean as a delayed response to external forcing? Geophys. Res. Lett., 31, L06203, doi:10.1029/ 2003GL019140.

Graf, W., H. Moser, H. Oerter, O. Reinwarth, and W. Stichler, 1988: Accumulation and ice-core studies on Filchner-Ronne Ice Shelf, Antarctica. Ann. Glaciol., 11, 23-31.

,-- , O. Reinwarth, J. Kipfstuhl, H. Oerter, A. Minikin, and D. Wagenbach, 1994: Snow-accumulation rates and isotopic content $\left({ }^{2} \mathrm{H},{ }^{3} \mathrm{H}\right)$ of near-surface firn from the FilchnerRonne Ice Shelf, Antarctica. Ann. Glaciol., 20, 121-128.

- O. Reinwarth, H. Oerter, C. Mayer, and A. Lambrecht, 1999: Surface accumulation on Foundation Ice Stream, Antarctica. Ann. Glaciol., 29, 23-28.

_- H. Oerter, O. Reinwarth, W. Stichler, F. Wilhelms, H. Miller, and R. Mulvaney, 2002: Stable isotope records from Dronning Maud Land, Antarctica. Ann. Glaciol., 35, 195201.

Gragnani, R., C. Smiraglia, B. Stenni, and S. Torcini, 1998: Chemical and isotopic profiles from snow pits and shallow firn cores on Campbell Glacier, northern Victoria Land, Antarctica. Ann. Glaciol., 27, 679-684.

Helsen, M. M., 2006: On the interpretation of stable isotopes in Antarctic precipitation. Ph.D. thesis, Institute of Marine and Atmospheric Research, Utrecht University, $158 \mathrm{pp}$. , R. S. W. van de Wal, M. R. van den Broeke, V. MassonDelmotte, H. A. J. Meijer, M. P. Scheele, and M. Werner, 2006: Modeling the isotopic composition of Antarctic snow using backward trajectories: Simulation of snow pit records. J. Geophys. Res., 111, D15109, doi:10.1029/2005JD006524.

,-- , and 2007: The isotopic composition of presentday Antarctic snow in a Lagrangian atmospheric simulation. J. Climate, 20, 739-756.

Hendricks, M. B., D. J. De Paolo, and R. C. Cohen, 2000: Space and time variation of $\delta \mathrm{D}$ and $\delta^{18} \mathrm{O}$ in precipitation: Can paleotemperature be estimated from ice cores? Global Biogeochem. Cycles, 14, 851-861.

Hoffmann, G., M. Werner, and M. Heimann, 1998: Water isotope module of the ECHAM atmospheric general circulation model: A study on timescales from days to several years. $J$. Geophys. Res., 103, 16 871-16 896.

_ J. Jouzel, and V. Masson, 2000: Stable water isotopes in atmospheric general circulation models. Hydrol. Processes, 14, 1385-1406.

Huybrechts, P., D. Steinhage, F. Wilhelms, and J. Bamber, 2000: Balance velocities and measured properties of the Antarctic ice sheet from a new compilation of gridded data for modelling. Ann. Glaciol., 30, 52-60.

Isaksson, E., and W. Karlén, 1994: High resolution climatic information obtained from short firn cores, Western Dronning Maud Land, Antarctica. Climatic Change, 26, 421-434.

- — N. Nundestrup, P. Mayewski, S. Whitlow, and M. Twickler, 1996: A century of accumulation and temperature changes in Dronning Maud Land, Antarctica. J. Geophys. Res., 101, 7085-7094.

, M. Van den Broeke, J.-G. Winther, L. Karlöf, J.-F. Pinglot, and N. Gundestrup, 1999: Accumulation and proxy- 
temperature variability in Dronning Maud Land, Antarctica, determined from shallow firn cores. Ann. Glaciol., 29, 17-22.

Jacobel, R. W., B. C. Welch, E. J. Steig, and D. P. Schneider, 2005: Glaciological and climatic significance of Hercules Dome, Antarctica: An optimal site for deep ice core drilling. J. Geophys. Res., 110, F01015, doi:10.1029/2004JF000188.

Johnsen, S. J., D. Dahl-Jensen, W. Dansgaard, and N. Gundestrup, 1995: Greenland paleotemperatures derived from GRIP bore hole temperature and ice core isotope profiles. Tellus, 47B, 624-629.

Joussaume, S., J. Jouzel, and R. Sadourny, 1984: A general circulation model of water isotope cycles in the atmosphere. $\mathrm{Na}$ ture, 311, 24-29.

Jouzel, J., 1986: Isotopes in cloud physics: Multistep and multistage processes. The Terrestrial Environment B, P. Fritz and J. C. Fontes, Eds., Vol. 2, Handbook of Environmental Isotopes Geochemistry, Elsevier, 61-112.

_ , and L. Merlivat, 1984: Deuterium and oxygen 18 in precipitation: Modelling of the isotopic effects during snow formation. J. Geophys. Res., 89, 11 749-11 757.

— and R. Koster, 1996: A reconsideration of the initial conditions used for stable water isotopes models. J. Geophys. Res., 101, 22 933-22 938.

L. Merlivat, D. Mazaudier, M. Pourchet, and C. Lorius, 1982: Natural tritium deposition and estimate of the mean global production rate. Geophys. Res. Lett., 9, 1191-1194.

,,- J. R. Petit, and C. Lorius, 1983: Climatic information over the last century deduced from a detailed isotopic record in the South Pole snow. J. Geophys. Res., 88, 2693-2703.

$\longrightarrow$, C. Lorius, J. R. Petit, C. Genthon, N. I. Barkov, V. M. Kotlyakov, and V. M. Petrov, 1987a: Vostok ice core: A continuous isotope temperature record over the last climatic cycle (160 000 years). Nature, 329, 402-408.

, G. L. Russel, R. J. Suozzo, R. D. Koster, J. W. C. White, and W. S. Broecker, 1987b: Simulations of the HDO and $\mathrm{H}_{2}{ }^{18} 0$ atmospheric cycles using the NASA GISS general circulation model: The seasonal cycle for present-day conditions. J. Geophys. Res., 92, 14 739-14 760.

- R. D. Koster, R. J. Suozzo, G. L. Russel, J. W. White, and W. S. Broecker, 1991: Simulations of the HDO and $\mathrm{H}_{2}{ }^{18} 0$ atmospheric cycles using the NASA GISS General Circulation Model: Sensitivity experiments for present-day conditions. J. Geophys. Res., 96, 7495-7507.

— last deglaciation in Antarctica. Climate Dyn., 11, 151-161.

—, F. Vimeux, N. Caillon, G. Delaygue, G. Hoffmann, V. Masson-Delmotte, and F. Parrenin, 2003: Magnitude of the isotope-temperature scaling for interpretation of central Antarctic ice cores. J. Geophys. Res., 108, 4361, doi:10.1029/ 2002JD002677.

Kato, K., W. Okitsugu, and S. Kazuhide, 1977: Oxygen isotopic composition of the surface snow in Mizuho Plateau. JARE Data Rep., 36, 158-169.

Kavanaugh, J. L., and K. M. Cuffey, 2003: Space and time variation of $\delta^{18} \mathrm{O}$ and $\delta \mathrm{D}$ in Antarctic precipitation revisited. Global Biogeochem. Cycles, 17, 1017, doi:10.1029/2002GB001910.

Koster, R. D., J. Jouzel, R. Suozzo, G. Russell, W. Broecker, D. Rind, and P. Eagleson, 1986: Global sources of local precipitation as determined by the NASA/GISS GCM. Geophys. Res. Lett., 13, 121-124.

,,,--- and -1992 : Origin of July Antarctic precipitation and its influence on deuterium content: A GCM analysis. Climate Dyn., 7, 195-203.
Krinner, G., O. Magand, I. Simmonds, C. Genthon, and J. L. Dufresne, 2007: Simulated Antarctic precipitation and surface mass balance at the end of the twentieth century. Climate Dyn., 28, 215-230.

Landais, A., and Coauthors, 2004a: A continuous record of temperature evolution over a whole sequence of DansgaardOeschger during Marine Isotopic Stage 4 (76 to $62 \mathrm{kyr}$ BP). Geophys. Res. Lett., 31, L22211, doi:10.1029/2004GL021193.

_, N. Caillon, A. Grachev, J. M. Barnola, J. Chappellaz, J. Jouzel, V. Masson-Delmotte, and M. Leuenberger, 2004b: Quantification of rapid temperature change during DO event 12 and phasing with methane inferred from air isotopic measurements. Earth Planet. Sci. Lett., 225, 221-232.

,-- J. Severinghaus, J. M. Barnola, C. Goujon, J. Jouzel, and V. Masson-Delmotte, 2004c: Isotopic measurements of air trapped in ice to quantify temperature changes. Compt. Rend. Geosci., 336, 963-970.

- and Coauthors, 2006: Firn-air $\delta^{15} \mathrm{~N}$ in modern polar sites and glacial-interglacial ice: A model-data mismatch during glacial periods in Antarctica. Quat. Sci. Rev., 25, 49-62.

- E. Barkan, and B. Luz, 2008: The record of $\delta^{18} \mathrm{O}$ and ${ }^{17} \mathrm{O}-$ excess in ice from Vostok, Antarctica, during the last 150000 years. Geophys. Res. Lett., 35, L02709, doi:10.1029/ 2007GL032096.

Lang, C., M. Leuenberger, J. Schwander, and J. Johnsen, 1999: $16^{\circ} \mathrm{C}$ rapid temperature variation in central Greenland 70000 years ago. Science, 286, 934-937.

Lhomme, N., G. K. C. Clarke, and C. Ritz, 2005: Global budget of water isotopes inferred from polar ice sheets. Geophys. Res. Lett., 32, L20502, doi:10.1029/2005GL023774.

Lipenkov, V., A. A. Ekaykin, N. I. Barkov, and M. Pourchet, 1998: On the relation between surface snow density in Antarctica and wind speed. Data Glaciol. Stud., 85, 148-158.

Lorius, C., and L. Merlivat, 1977: Distribution of mean surface stable isotope values in East Antarctica: Observed changes with depth in a coastal area. Isotopes and Impurities in Snow and Ice: Proc. of the Grenoble Symp. August/September 1975, Vienna, Austria, IAHS, 125-137.

,-- , and R. Hagemann, 1969: Variation in the mean deuterium content of precipitations in Antarctica. J. Geophys. Res., 74, 7027-7031.

Magand, O., M. Frezzotti, M. Pourchet, B. Stenni, L. Genoni, and M. Fily, 2005: Climate variability along latitudinal and longitudinal transects in East Antarctica. Ann. Glaciol., 39, 351358.

Masson-Delmotte, V., M. Delmotte, V. Morgan, D. Etheridge, T. van Ommen, S. Tartarin, and G. Hoffmann, 2003: Recent southern Indian Ocean climate variability inferred from a Law Dome ice core: New insights for the interpretation of coastal Antarctic isotopic records. Climate Dyn., 21, 151-166.

— B. Btenni, and J. Jouzel, 2004: Common millennial scale variability of Antarctic and Southern Ocean temperatures during the past 5000 years reconstructed from EPICA Dome $\mathrm{C}$ ice core. Holocene, 14, 145-151.

- and Coauthors, 2006: Past and future polar amplification of climate change: Climate model intercomparisons and icecore constraints. Climate Dyn., 26, 513-529.

Mayewski, P. A., and Coauthors, 1990: The Dominion Range ice core, Queen Maud Mountains, Antarctica-General site and core characteristics with implication. J. Glaciol., 36, 11-16.

— , and Coauthors, 2005: The International Trans-Antarctic Scientific Expedition (ITASE): An overview. Ann. Glaciol., 41, $180-185$. 
Merlivat, L., and J. Jouzel, 1979: Global climatic interpretation of the deuterium-oxygen 18 relationship for precipitation. $J$. Geophys. Res., 84, 5029-5033.

Monaghan, A. J., and Coauthors, 2006: Insignificant change in Antarctic snowfall since the International Geophysical Year. Science, 313, 827-831.

Monnin, E., and Coauthors, 2004: Evidence for substantial accumulation rate variability in Antarctica during the Holocene, through synchronization of $\mathrm{CO}_{2}$ in the Taylor Dome, Dome C and DML ice cores. Earth Planet. Sci. Lett., 224, 45-54.

Morgan, V. I., 1982: Antarctic ice sheet surface oxygen isotope values. J. Glaciol., 28, 315-323.

—, C. W. Wookey, J. Li, T. D. V. Ommen, W. Skinner, and M. F. Fitzpatrick, 1997: Site information and initial results from deep ice drilling on Law Dome. J. Glaciol., 43, 3-10.

Mosley-Thompson, E., 1996: Holocene climate changes recorded in an east Antarctica ice core. Climatic Variations and Forcing Mechanisms of the Last 2000 Years, P. D. Jones, R. S. Bradley, and J. Jouzel, Eds., NATO ASI Series, Vol. 41, Springer-Verlag, 263-279.

Motoyama, H., N. Hirasawa, K. Satow, and O. Watanabe, 2005: Seasonal variations in oxygen isotope ratios of daily collected precipitation and wind drift samples and in the final snow cover at Dome Fuji Station, Antarctica. J. Geophys. Res., 110, D11106, doi:10.1029/2004JD004953.

Neumann, T. A., and E. D. Waddington, 2004: Effects of firn ventilation on isotopic exchange. J. Glaciol., 169, 183-194.

,-- E. J. Steig, and P. M. Grootes, 2005: Non-climate influences on stable isotopes at Taylor Mouth, Antarctica. $J$. Glaciol., 51, 248-258.

Noone, D., 2006: Isotopic composition of water vapor modeled by constraining global climate simulations with reanalyses. $R e$ search Activities in Atmospheric and Oceanic Modeling, J. Cote, Ed., World Meteorological Organization, 2-37.

_ 2008: The influence of midlatitude and tropical overturning circulation on the isotopic composition of atmospheric water vapor and Antarctic precipitation. J. Geophys. Res., 113, D04102, doi:10.1029/2007JD008892.

— ice-core isotope data from analysis of modelled Antarctic precipitation. Ann. Glaciol., 27, 398-402.

$\longrightarrow$, and —, 2002a: Annular variations in moisture transport mechanisms and the abundance of $\delta^{18} \mathrm{O}$ in Antarctic snow. $J$. Geophys. Res., 107, 4742, doi:10.1029/2002JD002262.

$\longrightarrow$, and $-2002 \mathrm{~b}$ : Associations between $\delta^{18} \mathrm{O}$ of water and climate parameters in a simulation of atmospheric circulation for 1979-95. J. Climate, 15, 3150-3169.

— and - 2004: Sea ice control of water isotope transport to Antarctica and implications for ice core interpretation. $J$. Geophys. Res., 109, D07105, doi:10.1029/2003JD004228.

Oerter, H., W. Graf, F. Wilhelms, A. Minikin, and H. Miller, 1999: Accumulation studies on Amundsenisen, Dronning Maud Land, Antarctica, by means of tritium, dielectric profiling and stable-isotope measurements: First results from the 19951996 and 1996-97 field seasons. Ann. Glaciol., 29, 1-9.

,,-- H. Meyer, and F. Wilhelms, 2004: The EPICA ice core from Dronning Maud Land: First results from stable isotope measurements. Ann. Glaciol., 39, 1-6.

Parrenin, F., J. Jouzel, C. Waelbroeck, C. Ritz, and J.-M. Barnola, 2001: Dating of the Vostok ice core by an inverse method. $J$. Geophys. Res., 106, 31 837-31 851.

— modeling of the Vostok ice flow line and implication for the glaciological chronology of the Vostok ice core. J. Geophys. Res., 109, D20102, doi:10.1029/2004JD004561.

— , and Coauthors, 2007: 1-D-ice flow modelling at EPICA Dome C and Dome Fuji, East Antarctica. Climate Past, 3, 243-259.

Peel, D. A., 1992: Ice core evidence from the Antarctic Peninsula region. Climate since A.D. 1500, R. S. Bradley and P. D. Jones, Eds., Routledge, 549-571.

Petit, J. R., J. W. C. White, N. W. Young, J. Jouzel, and Y. S. Korotkevich, 1991: Deuterium excess in recent Antarctic snow. J. Geophys. Res., 96, 5113-5122.

Proposito, M., and Coauthors, 2002: Chemical and isotopic snow variability along the 1998 ITASE traverse from Terra Nova Bay to Dome C, East Antarctica. Ann. Glaciol., 35, 187-194.

Qin, D., and W. Wang, 1990: The historical climatic records in ice cores from the surface layer of Wilkes, Antarctica. Sci. China, 33, 460-466.

Reijmer, H., R. van den Broeke, and M. P. Scheele, 2002: Air parcel trajectories and snowfall related to five deep drilling locations in Antarctica based on the ERA-15 dataset. J. Climate, 15, 1957-1968.

Rozanski, K., L. Araguas-Araguas, and R. Gonfiantini, 1993: Isotopic pattern in modern global precipitation. Climate Change in Continental Isotopic Records, Geophys. Monogr., Vol. 78, Amer. Geophys. Union, 1-36.

Ruth, U., D. Wagenbach, R. Mulvaney, H. Oerter, W. Graf, H. Pulz, and G. Littot, 2004: Comprehensive 1000 year climate history from an intermediate depth ice core from the south dome of Berkner Island, Antarctica: Methods, dating and first results. Ann. Glaciol., 39, 146-154.

Salamatin, A. N., V. Y. Lipenkov, N. I. Barkov, J. Jouzel, J. R. Petit, and D. Raynaud, 1998: Ice-core age dating and palaeothermometer calibration on the basis of isotope and temperature profiles from deep boreholes at Vostok station (East Antarctica). J. Geophys. Res., 103, 8963-8977.

—, A. A. Ekaykin, and V. Y. Lipenkov, 2004: Modelling isotopic composition in precipitation in Central Antarctica. Mater. Glyatsiologicheskih Issled., 97, 24-34.

Satake, H., and K. Kawada, 1997: The quantitative evaluation of sublimation and the estimation of original hydrogen and oxygen of a firn core at East Queen Maud Land, Antarctica. Bull. Glacier Res., 15, 93-97.

Satow, K., 1977: Snow temperatures at a depth of 10 meters. JARE Data Rep., 36, 59-60.

- and O. Watanabe, 1990: Seasonal variation of oxygen isotopic composition of firn cores in the Antarctic ice sheet. Ann. Glaciol., 14, 256-260.

Schlosser, E., C. Reijmer, H. Oerter, and W. Graf, 2004: The influence of origin of precipitation on the $\delta^{18} \mathrm{O}$-T relationship at Neumayer Station, Ekströmisen, Antarctica. Ann. Glaciol., 39, 41-48.

Schmidt, G. A., G. Hoffmann, D. T. Shindell, and Y. Hu, 2005: Modeling atmospheric stable water isotopes and the potential for constraining cloud processes and stratosphere-troposphere water exchange. J. Geophys. Res., 110, D21314, doi:10.1029/2005JD005790.

_ A. N. Legrande, and G. Hoffmann, 2007: Water isotope expressions of intrinsic and forced variability in a coupled ocean-atmosphere model. J. Geophys. Res., 112, D10103, doi:10.1029/2006JD007781.

Schneider, D. P., and D. C. Noone, 2007: Spatial covariance of water isotope records in a global network of ice cores span- 
ning twentieth-century climate change. J. Geophys. Res., 112, D18105, doi:10.1029/2007JD008652.

— E. Steig, T. D. van Ommen, D. A. Dixon, P. A. Mayewski, J. M. Jones, and C. M. Bitz, 2006: Antarctic temperatures over the past two centuries from ice cores. Geophys. Res. Lett., 33, L16707, doi:10.1029/2006GL027057.

Severinghaus, J., T. Sowers, E. J. Brook, R. B. Alley, and M. Bender, 1998: Timing of abrupt climate change at the end of the Younger Dryas interval from thermally fractionated gases in polar ice. Nature, 391, 141-146.

Simmonds, I., and K. Keay, 2000: Mean Southern Hemisphere extratropical cyclone behavior in the 40-year NCEP-NCAR reanalysis. J. Climate, 13, 873-885.

$\longrightarrow,-$, and E. P. Lim, 2003: Synoptic activity in the seas around Antarctica. Mon. Wea. Rev., 131, 272-288.

Simões, J. C., F. A. Ferron, A. J. Aristarain, R. T. Bernardo, M. Stievenard, and M. Pourchet, 2004: Ice core study from the King George Island ice cap, South Shetlands, Antarctica. Pesqui. Antarct. Brasil, 4, 9-23.

Smith, B. T., T. D. van Ommen, and V. I. Morgan, 2002: Distribution of oxygen isotope ratios and snow accumulation rates in Wilhelm II Land, East Antarctica. Ann. Glaciol., 35, 107110.

Steig, E. J., and Coauthors, 1998: Synchronous climate changes in Antarctica and the North Atlantic. Science, 282, 92-95.

—, and Coauthors, 2005: High resolution ice cores from US ITASE (West Antarctica): Development and validation of chronologies and determination of precision and accuracy. Ann. Glaciol., 41, 77-84.

Stenni, B., and Coauthors, 1999: 200 years of isotope and chemical records in a firn core from Hercules Névé, northern Victoria Land, Antarctica. Ann. Glaciol., 29, 106-112.

- F. Serra, M. Frezzotti, V. Maggi, R. Traversi, S. Becagli, and R. Udisti, 2000: Snow accumulation rates in northern Victoria Land, Antarctica, by firn-core analysis. J. Glaciol., 46, 541-552.

—, V. Masson, S. J. Johnsen, J. Jouzel, A. Longinelli, E. Monnin, R. Roethlisberger, and E. Selmo, 2001: An oceanic cold reversal during the last deglaciation. Science, 293, 2074-2077.

—, M. Proposito, R. Gragnani, O. Flora, J. Jouzel, S. Falourd, and M. Frezzotti, 2002: Eight centuries of volcanic signal and climate change at Talos Dome (East Antarctica). J. Geophys. Res., 107, 4076, doi:10.1029/2000JD000317.

Sturm, K., G. Hoffmann, B. Langmann, and W. Stichler, 2005: Simulation of $\delta^{18} \mathrm{O}$ in precipitation by the regional circulation model REMOiso. Hydrol. Processes, 19, 3425-3444.

Thompson, L. G., D. A. Peel, E. Mosley-Thompson, R. Mulvaney, J. Dai, P. N. Lin, M. E. Davis, and C. F. Raymond, 1994: Climate since AD 1510 on Dyer Plateau, Antarctic Peninsula: Evidence for recent climate change. Ann. Glaciol., 20, 420-426.

Turner, J., T. A. Lachlan-Cope, S. Colwell, G. J. Marshall, and W. M. Connolley, 2006: Significant warming of the Antarctic winter troposphere. Science, 311, 1914-1917.
Urbini, S., M. Frezzotti, S. Gandolfi, C. Vincent, C. Scarchilli, L. Vittuari, and M. Fily, 2008: Historical behaviour of Dome C and Talos Dome (East Antarctica) as investigated by snow accumulation and ice velocity measurements. Global Planet. Change, 60, 576-588.

Van de Berg, W. J., 2008: Present-day climate of Antarctica: A study with a Regional Atmospheric Climate Model. Ph.D. thesis, Utrecht University, 138 pp.

- M. R. Van den Broeke, C. H. Reijmer, and E. Van Meijgaard, 2006: Reassessment of the Antarctic surface mass balance using calibrated output of a regional atmospheric climate model. J. Geophys. Res., 111, D11104, doi:10.1029/ 2005JD006495.

van den Broeke, M. R., and N. P. M. van Lipzig, 2005: Changes in Antarctic temperature, wind and precipitation in response to the Antarctic Oscillation. Ann. Glaciol., 39, 119-126.

Vimeux, F., V. Masson, J. Jouzel, M. Stievenard, and J. R. Petit, 1999: Glacial-interglacial changes in ocean surface conditions in the Southern Hemisphere. Nature, 398, 410-413.

,,,--- J. R. Petit, E. J. Steig, M. Stievenard, R. Vaikmae, and J. W. C. White, 2001: Holocene hydrological cycle changes in the Southern Hemisphere documented in East Antarctic deuterium excess records. Climate Dyn., 17, 503513.

Wagenbach, D., W. Graf, A. Minikin, U. Trefzer, J. Kipfstuhl, H. Oerter, and N. Blindow, 1994: Reconnaissance of chemical and isotopic firn properties on top of Berkner Island, Antarctica. Ann. Glaciol., 20, 307-312.

Watanabe, O., 1977: Stratigraphic observations of surface snow cover. JARE Data Rep., 36, 61-125.

- J. Jouzel, S. Johnsen, F. Parrenin, H. Shoji, and N. Yoshida, 2003: Homogeneous climate variability across East Antarctica over the past three glacial cycles. Nature, 422, 509-512.

Werner, M., and M. Heimann, 2002: Modeling interannual variability of water isotopes in Greenland and Antarctica. J. Geophys. Res., 107, 4001, doi:10.1029/2001JD900253.

$[,-$, and G. Hoffmann, 2001: Isotopic composition and origin of polar precipitation in present and glacial climate simulations. Tellus, 53B, 53-71.

Xiao, C., J. Ren, D. Qin, Z. Li, Z. Sun, and I. Allison, 2001: Complexity of the climatic regime over the Lambert Glacier basin of the East Antarctic ice sheet: Firn core evidences. $J$. Glaciol., 47, 160-163.

—, I. Allison, J. W. Ren, D. H. Qin, M. J. Zhang, and Z. Q. Li, 2004: Meteorological and glaciological evidence for different climatic variations on the east and west side of the Lambert Glacier basin, Antarctica. Ann. Glaciol., 39, 188-194.

Yao, T., J. R. Petit, J. Jouzel, C. Lorius, and P. Duval, 1990: Climatic record from an ice margin area in East Antarctica. Ann. Glaciol., 14, 323-327.

Yoshimura, K., T. Oki, and K. Ichiyanagi, 2004: Evaluation of two-dimensional atmospheric water circulation fields in reanalyses by using precipitation isotopes databases. J. Geophys. Res., 109, D20109, doi:10.1029/2004JD004764. 